\title{
FROM BENCHTOP TO CLINIC: A TRANSLATIONAL ANALYSIS OF THE IMMUNE RESPONSE TO SUBMICRON TOPOGRAPHY AND ITS RELEVANCE TO BONE HEALING
}

\author{
L.A. van Dijk ${ }^{1,2,}$, F. de Groot ${ }^{1, \S}$, H. Yuan ${ }^{1}$, C. Campion ${ }^{1}$, A. Patel ${ }^{3}$, K. Poelstra ${ }^{4}$ and J.D. de Bruijn ${ }^{1,5, *}$ \\ ${ }^{1}$ Kuros Biosciences, Bilthoven, the Netherlands \\ ${ }^{2}$ University Medical Center Utrecht, Department of Oral and Maxillofacial Surgery, Utrecht, \\ the Netherlands \\ ${ }^{3}$ Northwestern Medicine Spine Center, Chicago, IL, USA \\ ${ }^{4}$ The Robotic Spine Institute of Silicon Valley, Las Vegas, NV, USA \\ ${ }^{5}$ School of Engineering and Materials Science, Queen Mary University of London, London, UK \\ $\S$ These authors contributed equally to this work
}

\begin{abstract}
Proper regulation of the innate immune response to bone biomaterials after implantation is pivotal for successful bone healing. Pro-inflammatory M1 and anti-inflammatory M2 macrophages are known to have an important role in regulating the healing response to biomaterials. Materials with defined structural and topographical features have recently been found to favourably modulate the innate immune response, leading to improved healing outcomes. Calcium phosphate bone grafts with submicron-sized needle-shaped surface features have been shown to trigger a pro-healing response through upregulation of M2 polarised macrophages, leading to accelerated and enhanced bone regeneration. The present review describes the recent research on these and other materials, all the way from benchtop to the clinic, including in vitro and in vivo fundamental studies, evaluation in clinically relevant spinal fusion models and clinical validation in a case series of 77 patients with posterolateral and/or interbody fusion in the lumbar and cervical spine. This research demonstrates the feasibility of enhancing biomaterial-directed bone formation by modulating the innate immune response through topographic surface features.
\end{abstract}

Keywords: Bone graft materials, surface topography, osteoinduction, macrophages, osteoimmunology, spine fusion.

*Address for correspondence: Prof. Joost D. de Bruijn,Professor Bronkhorstlaan 10, building 48, 3723 MB Bilthoven, the Netherlands.

Telephone number: +31 302297280 Email: j.d.debruijn@qmul.ac.uk

Copyright policy: This article is distributed in accordance with Creative Commons Attribution Licence (http://creativecommons.org/licenses/by-sa/4.0/).

\begin{tabular}{|c|c|c|c|}
\hline & List of Abbreviations & $\mathrm{BMP}$ & bone morphogenetic protein \\
\hline & & CCL & C-C motif chemokine ligand \\
\hline $\mathrm{ACDF}$ & anterior cervical discectomy and & $\mathrm{CD}$ & cluster of differentiation \\
\hline & fusion & CTSK & cathepsin $\mathrm{K}$ \\
\hline ALP & alkaline phosphatase & ELISA & enzyme-linked immunosorbent \\
\hline $\mathrm{BCP}$ & biphasic calcium phosphate & & assay \\
\hline $\mathrm{BCP}_{\mu \mathrm{m}}$ & $\begin{array}{l}\text { BCP with surface features in the } \\
\text { micron range }\end{array}$ & GAPDH & $\begin{array}{l}\text { glyceraldehyde 3-phosphate } \\
\text { dehydrogenase }\end{array}$ \\
\hline $\mathrm{BCP}_{<u m}$ & $\mathrm{BCP}$ with surface features in the & HA & hydroxyapatite \\
\hline & submicron range & IL & interleukin \\
\hline BG & $45 S 5$ bioglass & MSC & mesenchymal stem cell \\
\hline $\mathrm{BG}_{\mu \mathrm{m}}$ & BG with surface features in the & nano-HA & nanocrystalline hydroxyapatite \\
\hline & micron range & PCF & posterior cervical fusion \\
\hline BMA & bone marrow aspirate & PCL & poly( $\varepsilon$-caprolactone) \\
\hline BMDM & bone-marrow-derived macrophages & PLF & posterolateral fusion \\
\hline BMI & body mass index & poly-HEMA & poly(2-hydroxyethyl methacrylate) \\
\hline
\end{tabular}




\begin{tabular}{|c|c|}
\hline ROCK & rho-associated protein kinase \\
\hline RT-qPCR & $\begin{array}{l}\text { quantitative reverse transcription } \\
\text { polymerase chain reaction }\end{array}$ \\
\hline SEM & scanning electron microscopy \\
\hline SLA & $\begin{array}{l}\text { titanium sandblasted, large grit, } \\
\text { acid-etched surface }\end{array}$ \\
\hline Src & $\begin{array}{l}\text { proto-oncogene tyrosine-protein } \\
\text { kinase Src }\end{array}$ \\
\hline TCP & tricalcium phosphate \\
\hline $\mathrm{TCP}_{\mu \mathrm{m}}$ & $\begin{array}{l}\mathrm{TCP} \text { with surface features in the } \\
\text { micron range }\end{array}$ \\
\hline $\mathrm{TCP}_{<\mu \mathrm{m}}$ & $\begin{array}{l}\text { TCP with surface features in the } \\
\text { submicron range }\end{array}$ \\
\hline TGF- $\beta 1$ & transforming growth factor $\beta 1$ \\
\hline TNF- $\alpha$ & tumour necrosis factor $\alpha$ \\
\hline TRAP & tartrate-resistant acid phosphatase \\
\hline$\mu \mathrm{CT}$ & micro-computed tomography \\
\hline
\end{tabular}

\section{Introduction}

Over the past two decades, the number of spinal fusions performed annually has risen rapidly to more than 770,000 procedures in the USA alone (Millennium Research Group, 2016). Considering that non-union rates of spinal fusion are reported as high as $17 \%$ and the average rate of revision surgery rate is $10 \%$, it is evident that there is an increasing need for improved treatment modalities (Hsu et al., 2012; Mabud et al., 2017). Bone-graft type affects spinal fusion rates by up to $60 \%$ and certain bone-graft categories, including synthetic bone-graft substitutes, have shown relatively good outcomes (Hsu et al., 2012; Morris et al., 2018). An additional benefit of synthetic bone-graft substitutes is that they eliminate the need for invasive harvesting of autologous bone, which can lead to donor-site morbidity (Scheufler and Diesing, 2015).

Calcium phosphates have been extensively researched as synthetic bone-graft materials due to their excellent biocompatibility and innate osteoconductive properties, related to their similar chemical composition to native-bone mineral (Dorozhkin, 2013). Calcium phosphate bone grafts with submicron surface features have been shown to also have osteoinductive capacity and have demonstrated enhanced orthotopic bone formation when compared to conventional graft materials (Habibovic et al., 2006; Van Dijk et al., 2020). Therefore, osteoinductive calcium phosphate bone grafts provide a promising solution for spinal fusion and other bone grafting surgery.

To better understand which of the many bone graft properties lead to an optimal healing response, graft materials should be evaluated by biomaterials science, i.e. the study of the interaction between physicochemical material factors and biological factors. Indeed, the biological response to implanted materials is dependent on the material properties and associated cell and tissue responses following implantation (Brown et al., 2012; Davenport Huyer et al., 2020). While bone biomaterials research previously focused predominantly on the response of bone-lineage cells to materials (Jablonská et al., 2020; Thalji and Cooper, 2014), the recent interest in osteoimmunology has resulted in an increasing number of studies evaluating the response of the immune system (Chen et al., 2016; Miron and Bosshardt, 2016).

The initial response from cells of the innate immune system is pivotal for the further healing cascade after implantation of a graft material (Wynn and Vannella, 2016). During this response, macrophages are among the first cells to colonise an implant and are known to have a key regulatory role during healing and the subsequent reaction to implanted materials (Klopfleisch, 2016; Klopfleisch and Jung, 2017). Macrophages are highly plastic cells that swiftly respond to their micro-environment by adopting distinct phenotypes, broadly categorised into a pro-inflammatory subtype (classically activated or M1 macrophage) and an anti-inflammatory subtype (alternatively activated or M2 macrophage). Although both subtypes have an important role in the normal healing response, the prolonged presence of inflammatory M1 macrophages can exacerbate tissue injury and prevent biomaterial integration (Chen et al., 2016; Klopfleisch, 2016; Wynn and Vannella, 2016). M2-like osteal macrophages (OsteoMacs) have been shown to have an important regulatory role in bone tissue and M2 macrophage activation during bone repair with biomaterials has been associated with enhanced healing outcomes (Hachim et al., 2017; Mahon et al., 2020).

The present review is a bench-to-bedside translational analysis of osteoinductive calcium phosphate bone grafts with submicron surface topography that can modulate the innate immune response. It discusses recently published and unpublished research on how materials with specific structural features or surface topographies direct M2 macrophage polarisation, resulting in enhanced bone healing characteristics in vivo. This analysis of the literature may provide useful insights for future biomaterial design for bone-graft surgery.

\section{Empirical data indicate that size and shape of a surface topography dictate the osteoinductive potential of calcium phosphates}

Around the mid- $20^{\text {th }}$ century, research by Marshall Urist on decalcified bone led to the discovery and definition of the process of osteoinduction, i.e. the induction of de novo bone formation through cellular differentiation into bone-forming cells, often demonstrated by ectopic implantation of tissues or materials (Barradas et al., 2011; Urist, 1965). Although Urist and Strates (1971) identified BMPs as the sole trigger of osteoinduction, later discoveries indicated that synthetic materials, such as poly-HEMA sponges, titanium and different ceramics, could trigger ectopic bone formation without apparent involvement of BMPs (Barradas et al., 2011). The 
osteoinductive potential of synthetic materials was linked to specific physical properties such as threedimensional architecture, macropore configuration and surface structure (Heughebaert et al., 1988; Klein et al., 1994; Ripamonti et al., 2011; Yamasaki and Sakai, 1992; Yuan et al., 1999). Recently, material scientists have managed to enhance this biological outcome by tuning the physical properties of biomaterials using, in particular, surface features - resulting in materials with enhanced osteoinductive potential (Duan et al., 2019; Yuan et al., 2010). Osteoinductive calcium phosphate bone grafts have demonstrated superior bone-healing potential compared to conventional bone graft materials in challenging bone-defect models, without the drawbacks associated with autograft harvesting or the application of exogenous growth factors (Habibovic et al., 2006; Yuan et al., 2010).

This line of research demonstrated that including surface features at the submicron-sized level has a striking impact on osteoinduction. Duan et al. (2019) prepared calcium phosphate materials with surface topographies comprising either grain-shaped (TCP) or needle-shaped surface crystals (BCP) of either $\mu \mathrm{m}$ - $\left(\mathrm{TCP}_{\mu \mathrm{m}}, \mathrm{BCP}_{\mu \mathrm{m}}\right)$ or submicron-scale dimensions $\left(\mathrm{TCP}_{<\mu \mathrm{m}^{\prime}}, \mathrm{BCP}_{<\mu \mathrm{m}}\right)$, which were then implanted in the paraspinal muscles of canines (Fig. 1). Fluorochrome labels injected at week 3 (calcein), week 6 (xylenol orange) and week 9 (tetracycline) post-implantation were used to visualise bone formation dynamics. After 12 weeks, animals were sacrificed and implants analysed. Ectopic bone formation took place only in the implants with submicron surface features $\left(\mathrm{TCP}_{<\mu \mathrm{m}}, \mathrm{BCP}_{<\mu \mathrm{m}}\right)$, both having similar bone incidence ( 8 out of 8$)$ and bone quantities $(24.5 \pm 4.3 \%$ vs. $23.9 \pm 6.3$ ). However, the kinetics of bone formation were significantly different in each submicron material, as demonstrated by fluorochrome marker deposition. The xylenol orange fluorescence marker, indicating bone formed between 3 and 6 weeks, was significantly more present in the submicron needle-shaped topography $\left(\mathrm{BCP}_{<\mu \mathrm{m}}\right)$ compared to the submicron grain-shaped topography $\left(\mathrm{TCP}_{<\mu \mathrm{m}}\right)$. Indeed, for $\mathrm{BCP}_{<\mu m^{\prime}}$ new bone formed between 3 and 6 weeks was identified in 5 out of 8 implants and in a total of 21 independent locations in histological sections. This early bone formation was significantly enhanced compared to $\mathrm{TCP}_{<\mu \mathrm{m}^{\prime}}$ where only 2 out of 8 implants had incidence of bone formed between 3 and 6 weeks, and was observed in only 2 locations in histological sections. In other words, the submicron needle-shaped topography led to accelerated bone formation in a non-bony environment without the aid of exogenous biological growth factors.

The cellular events preceding early bone formation are likely to play a role in accelerated ectopic bone formation by calcium phosphate with submicron needle-shaped topography. This specifically entails the innate immune response to the material, involving macrophage recruitment and polarisation in reaction to the surface topography. This hypothesis is supported by results from Davison et al. (2014a),
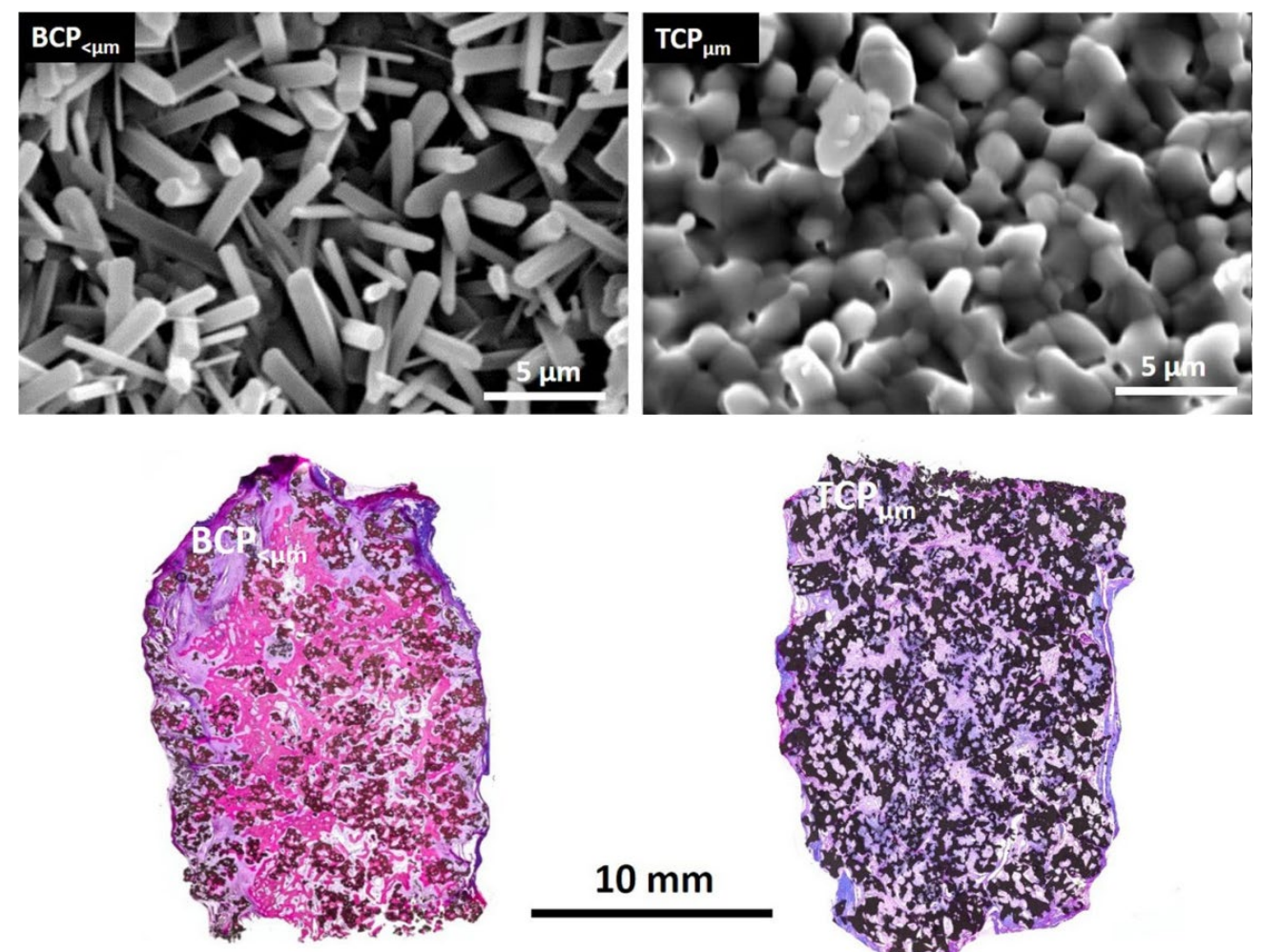

$10 \mathrm{~mm}$

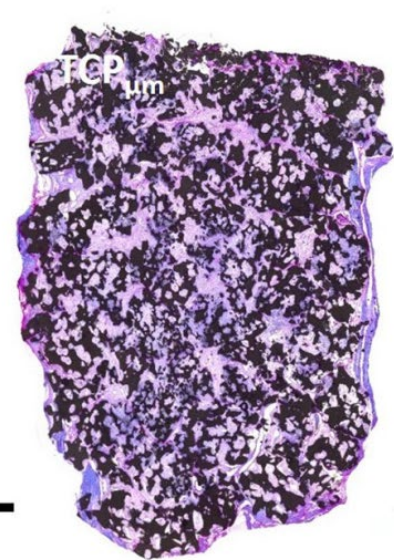

Fig. 1. Submicron needle-shaped topography induces ectopic bone formation. Top: SEM of calcium phosphate materials with submicron needle-shaped features $\left(\mathrm{BCP}_{<\mu \mathrm{m}}\right)$ and conventional micro-scale surface structure $\left(\mathrm{TCP}_{\mu \mathrm{m}}\right)$. Bottom: histology of $\mathrm{BCP}_{<\mu \mathrm{m}}$ and $\mathrm{TCP}_{\mu \mathrm{m}}$ explanted 12 weeks after ectopic implantation in paraspinal muscle of canines, indicating osteoinduction by $\mathrm{BCP}_{<\mu \mathrm{m}}$ (basic fuchsin/methylene blue). Adapted from Duan et al. (2019). 
who demonstrated that depletion of macrophages in the vicinity of calcium phosphate with submicron surface features directly inhibits ectopic bone formation in vivo. Other studies have shown that surface topography of implanted biomaterials can impact the phenotype of macrophages (Bota et al., 2010; Hotchkiss et al., 2016; Luu et al., 2015).

The next section of the review will describe published studies as well as unpublished findings by the authors showing macrophage polarisation in response to calcium phosphates and other biomaterials with defined structural features.

\section{Structural and topographical features of calcium phosphate and other biomaterials can upregulate M2 macrophages in vitro}

In recent years, an increasing number of studies have investigated the response of macrophages to biomaterials with specific structural or topographical features. These studies have consistently demonstrated a relationship between structural and topographical features and macrophage phenotype and associated regenerative microenvironment. Recently, Yang et al. (2019) have demonstrated that certain topographies of calcium phosphates can be used to modulate macrophage phenotype. They evaluated the response of murine RAW 264.7 cells to various surfaces of hierarchical, micropatterned nanoneedle-structured HA. They further determined that micro/nano hierarchical structures with defined pattern size could either promote or alleviate macrophage polarisation, which subsequently enhances or inhibits downstream osteogenic differentiation and angiogenic activity of cells in vitro. The influence of surface features on macrophage phenotype was further identified in a study by Li et al. (2019) who showed that porous HA with a microgrooved surface could suppress the inflammatory response in RAW264.7 cells compared to HA without microgrooves, leading to enhanced osteogenic differentiation of MSCs in vitro. Other studies have evaluated the response of macrophages to nano-HA, which contains a surface structure with a grain size of up to $100 \mathrm{~nm}$. Nano-HA was shown to have an anti-inflammatory effect on RAW264.7 cells and mouse peritoneal macrophage in vitro (Linares et al., 2016). In another study, Mahon et al. (2020) demonstrated that biomimetic nano-HA, in contrast with micron-sized HA, can upregulate human M2 macrophages in vitro, leading to augmented downstream osteogenesis and angiogenesis. This material demonstrated accelerated bone formation following implantation into a rat femoral defect model. Lebre et al. (2017) reported that the size and shape of nano-HA and micro-HA particles can strongly influence the inflammatory response in vitro and in vivo by controlling innate immune cell recruitment and cytokine production. These findings clearly indicate the role of specific structural and topographical features of calcium phosphates in the inflammatory response as well as in the regulation of macrophage phenotype and associated regenerative microenvironment.

\section{M2 macrophage polarisation on BCP with submicron surface topography}

In an unpublished work by the authors, the response of human macrophages to an osteoinductive BCP with submicron, needle-shaped topography was evaluated. Human macrophages derived from the monocytic cell line THP-1 were cultured for $4 \mathrm{~d}$ in vitro on BCP with submicron needle-shaped topography $\left(\mathrm{BCP}_{<\mu \mathrm{m}}\right)$, conventional tricalcium phosphate $\left(\mathrm{TCP}_{\mu \mathrm{m}}\right)$ and bioglass $\left(\mathrm{BG}_{\mu \mathrm{m}}\right)$. M2 and M1 cytokines expressed by these cells were quantified by ELISA and macrophage morphology was analysed by SEM. M2 macrophage markers TGF- $\beta 1$ and CCL18 were expressed to a greater extent on $\mathrm{BCP}_{<\mu \mathrm{m}}$ than on $\mathrm{TCP}_{\mu \mathrm{m}}$, while $\mathrm{M} 1$ macrophage markers TNF- $\alpha$ and IL-1 $\beta$ were expressed to a greater extent on $\mathrm{TCP}_{\mu \mathrm{m}}$ than on $\mathrm{BCP}_{<\mu \mathrm{m}}$ (Fig. 2). No cytokine signals could be detected in the $\mathrm{BG}_{\mu \mathrm{m}}$ group, which corresponded to the SEM observations, as macrophages were not found attached to the surface of $\mathrm{BG}_{\mu \mathrm{m}}$. This in vitro experiment demonstrated that the submicron topography of $\mathrm{BCP}_{<\mu \mathrm{m}}$ could upregulate M2 macrophages after $4 \mathrm{~d}$ of culture.

The morphological appearance of the macrophages on the needle-shaped surface texture was predominately large ( $>20 \mu \mathrm{m}$ in diameter) and appeared to have fused together, through several cellcell connections, into a highly networked population on $\mathrm{BCP}_{<\mu \mathrm{m}}$ (Fig. 3). These large macrophages were only observed on $\mathrm{BCP}_{<\mu \mathrm{m}}$. This spreading and connecting cellular network is indicative of the M2 macrophage phenotype when derived from THP-1 monocytes (Kumar et al., 2016; Reeves et al., 2015). In contrast, mononuclear cells, 5-10 $\mu \mathrm{m}$ in diameter, dispersed on the surface with no evidence of fusion were exclusively observed on the standard $\mathrm{TCP}_{\mu \mathrm{m}}$ material (Fig. 3). The morphology of the macrophages and the lack of spreading on $\mathrm{TCP}_{\text {um }}$ are suggestive of the M1 macrophage phenotype (Kumar et al., 2016; Reeves et al., 2015). Cells were absent on the surface of $\mathrm{BG}_{\mu \mathrm{m}^{\prime}}$ indicating an inability of this material to support cell attachment. The upregulation of M2 cytokines and interconnected cellular network of macrophages in contact with $\mathrm{BCP}_{<\mu \mathrm{m}}$ confirmed M2 macrophage polarisation, in contrast with the other graft materials, suggesting a pro-healing response to the submicron needle-shaped topography.

In another unpublished work, a yet more relevant in vitro model of the human innate immune response was utilised. Primary human macrophages obtained from 3 human donors were used to assess the response to a submicron needle-shaped surface. M0 macrophages derived from primary CD14 ${ }^{+}$ monocytes isolated from buffy coats were cultured for $4 \mathrm{~d}$ on $\mathrm{BCP}_{<\mu \mathrm{m}}$ discs and a tissue culture plastic control. The expression of M1 and M2 markers was compared with quantification at the protein level 
by ELISA and at the gene level by RT-qPCR. The resulting cell morphology was analysed by SEM. This experiment confirmed earlier findings using THP-1 cells. On $\mathrm{BCP}_{<\mu m^{\prime}}$ macrophages secreted high levels of the M2 marker CCL18, while the M1 marker CCL5 could not be detected (Fig. 4). At the gene level, the same polarisation trend was observed (Fig. 5). The
M2 gene markers CCL18, CD206 and CD163 showed higher expression on $\mathrm{BCP}_{<\mu \mathrm{m}}$ compared to the flat surface control. M2 gene upregulation on $\mathrm{BCP}_{<\mu \mathrm{m}}$ was significant for each of the 3 genes compared to macrophages cultured on flat surfaces, with a maximum fold increase of 27.5 for CD206, followed by 3.9 and 2.3 for CD163 and CCL18, respectively.
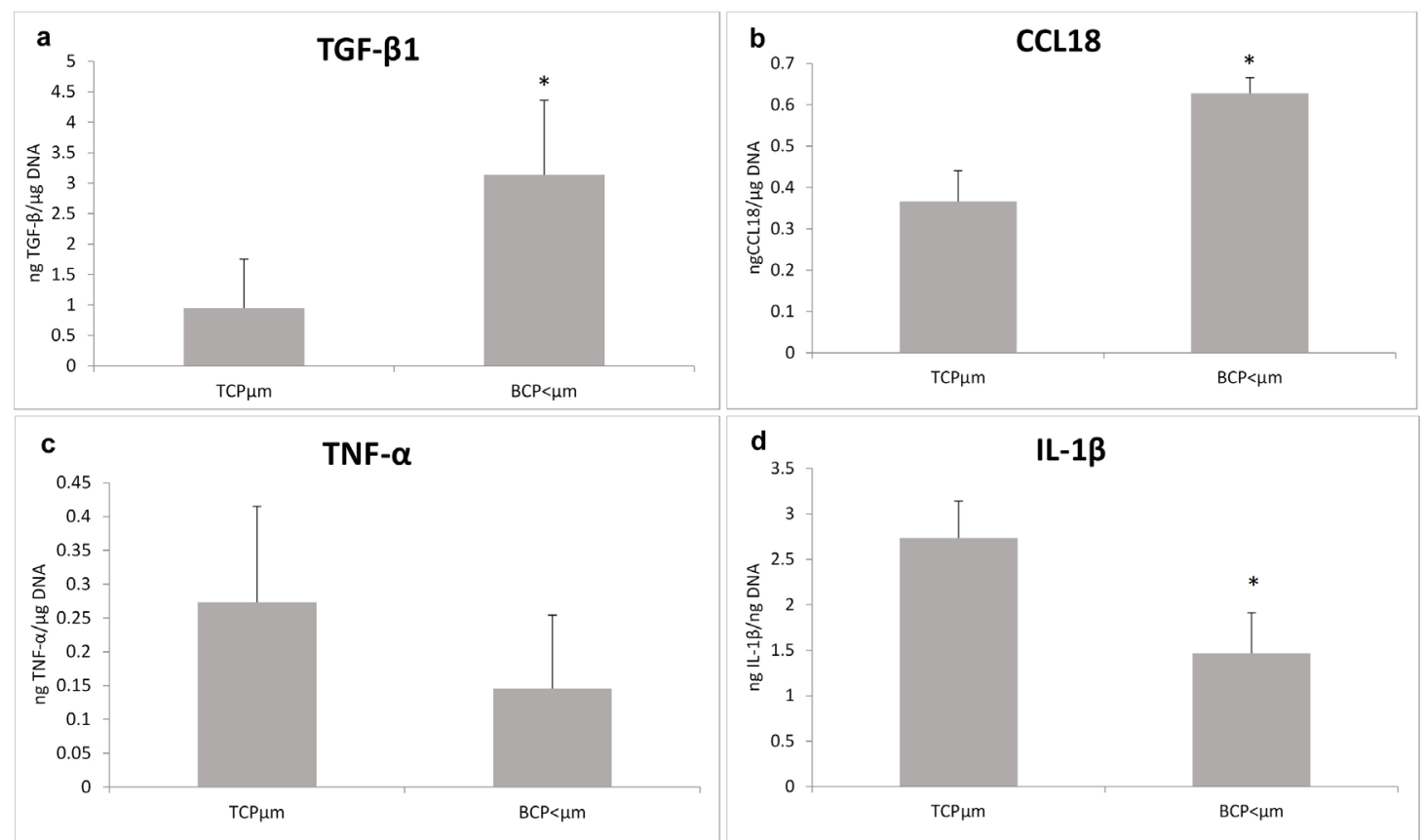

Fig. 2. Levels of protein markers in cultures of human THP-1 macrophages on $\mathrm{BCP}_{<\mu \mathrm{m}}$ and $\mathrm{TCP}_{\mu \mathrm{m}}$. Expression of pro-healing M2-markers (a) TGF- $\beta 1$ and (b) CCL18 and pro-inflammatory M1-markers (c) TNF- $\alpha$ and (d) IL-1 $\beta$ at day $4\left(n=4,{ }^{*} p<0.05\right)$. Original results from the authors (2021).
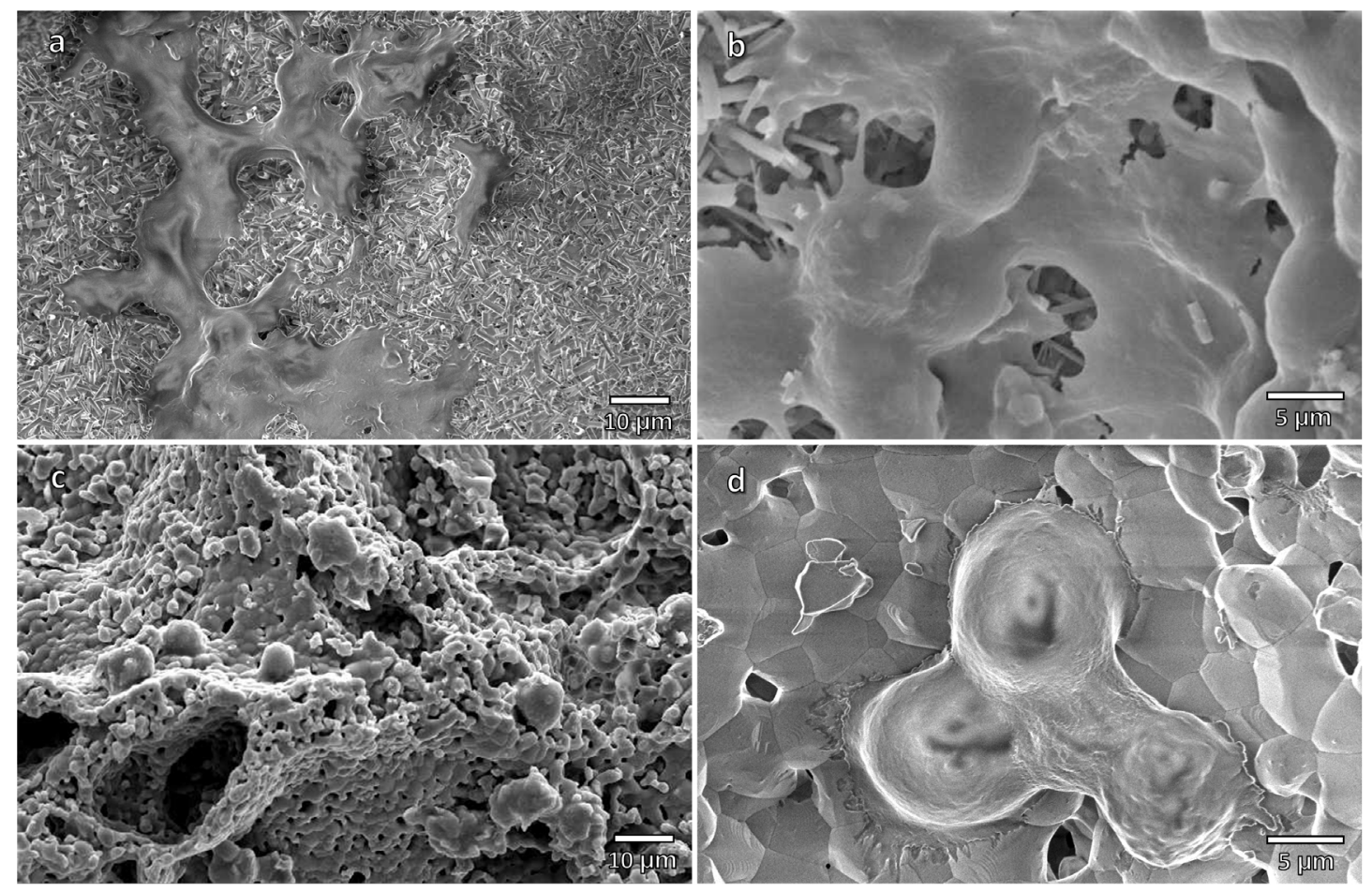

Fig. 3. SEM images of human THP-1 macrophages cultured on $\mathrm{BCP}_{<\mu \mathrm{m}}$ and $\mathrm{TCP}_{\mu \mathrm{m}}$. Pictured are macrophages on the needle-shaped topography of $\mathrm{BCP}_{<\mu m^{\prime}}$ at (a) low (b) and high magnification, and on $\mathrm{TCP}_{\mu \mathrm{m}^{\prime}}$ at (c) low and (d) high magnification. No macrophages could be found on bioactive glass in $B G_{\mu m}$ (images not shown). Original results from the authors (2021). 
The M1 gene markers CCL5, CCL2 and IL-1 $\beta$ showed a slightly higher expression on $\mathrm{BCP}_{<u m}$ compared to the flat surface control (Fig. 5). Nonetheless, downregulation was observed for CCL5 $(<0.75)$ and upregulation was limited to 1.5 and 1.7 for CCL2 and $I L-1 \beta$, respectively. Of the 6 genes analysed, 4 showed a significant trend towards a pro-healing mechanism, elicited by the surface features of $\mathrm{BCP}_{<\mu \mathrm{m}}$.

The morphology of the macrophages cultured on $\mathrm{BCP}_{<\mu \mathrm{m}}$ was prominently elongated (15-50 $\mu \mathrm{m}$ in length), connected with each other and with few protrusions (Fig. 6a-c). A limited subset of rounder granular cells of $5-10 \mu \mathrm{m}$ in diameter could also be observed. The elongated morphology and connected cellular network confirmed the M2 macrophage phenotype, as opposed to M1 polarised macrophages, which are less prone to elongation and spreading with high granulation when derived from CD14 monocytes (Buchacher et al., 2015; Zarif et al., 2016). Therefore, based on the quantitative

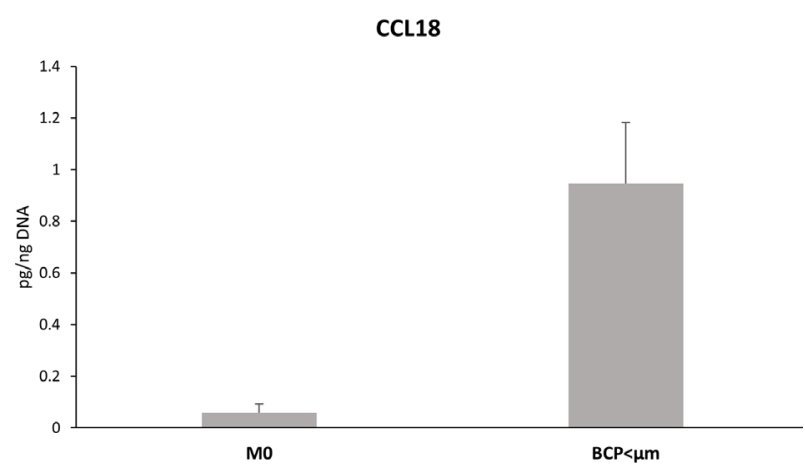

Fig. 4. Expression of pro-healing M2-marker CCL18. Protein expression was measured after $4 \mathrm{~d}$ of culture $(n=3, p<0.05)$ compared to flat tissue culture polystyrene $(\mathrm{M} 0)$. Original results from the authors (2021). analysis of protein markers, gene expression and SEM observations of cell morphologies, the macrophages present on $\mathrm{BCP}_{<\mu \mathrm{m}}$ were mostly associated with the M2 macrophage phenotype, again confirming a prohealing response of macrophages cultured on the submicron needle-shaped surface structure.

\section{M2 macrophage polarisation on other biomaterials with specific surface topographies}

Besides calcium phosphates, other materials with specific surface features have the ability to upregulate M2 macrophages on their surfaces. Extensive research has been performed on titanium materials with specific surface topographies that have demonstrated this propensity. A recent study by Yang et al. (2021) evaluated the in vitro response of murine BMDMs to titanium with three different surface topographies created by various surface treatments. While the SLA control material had a surface with microscale irregular concavities and ridge structure, two experimental materials subjected to alkali-heat treatment had micro/nanonet surface structures with different pore sizes. These experimental surface topographies induced an elongated phenotype in adherent macrophages and phenotype characterisation confirmed M2 macrophage upregulation versus M1 activation on the control material. In in vivo evaluation, the micro/ nano-net surface topographies were associated with larger numbers of M2 macrophages, enhanced vascularisation, more bone formation at the material surface and enhanced osseointegration compared to SLA titanium surfaces (Yang et al., 2021).

Other relevant research involving titanium has focused on macrophage response to topographies of $\mathrm{TiO}_{2}$ nanotubes. Several studies have consistently reported findings of M2 macrophage phenotype upregulation on surface topographies of $\mathrm{TiO}_{2}$
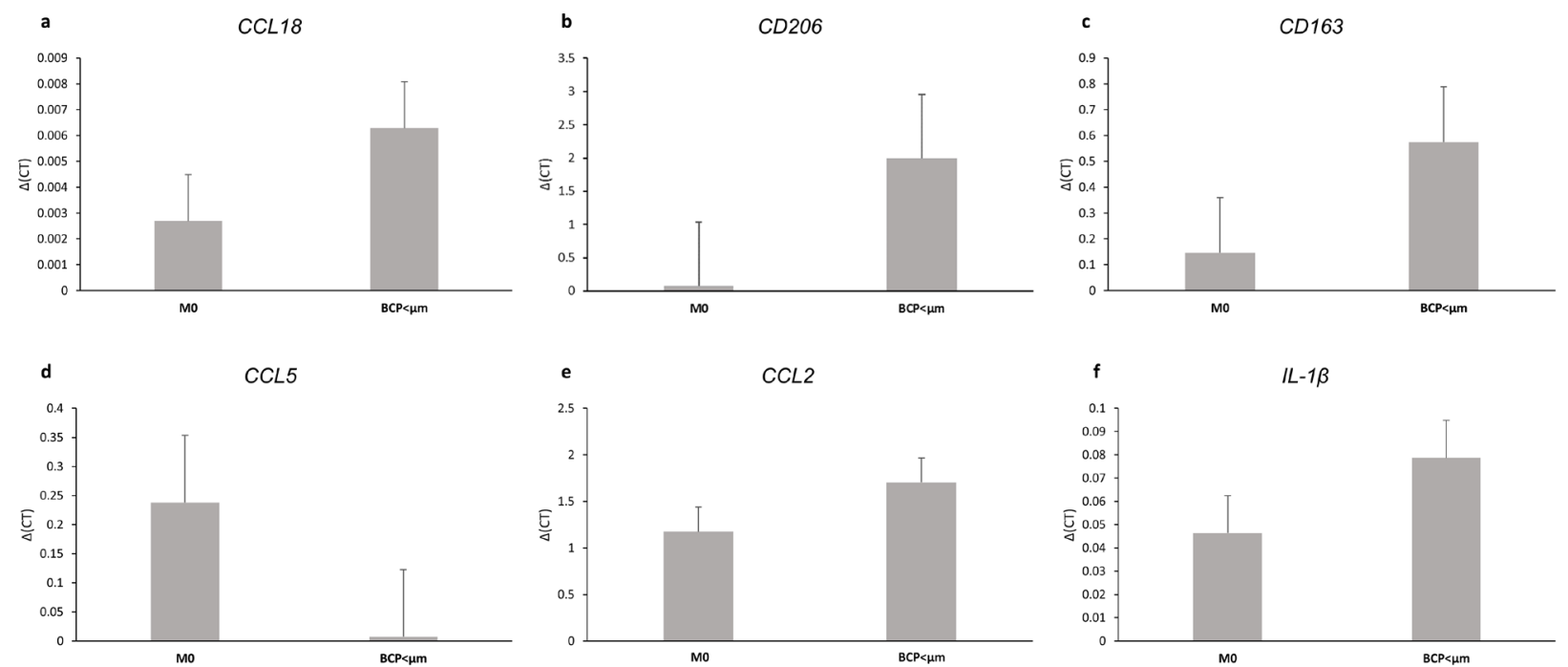

Fig. 5. Expression of gene markers in human primary macrophages cultured on $\mathrm{BCP}_{<\mu \mathrm{m}}$ compared to tissue culture polystyrene (M0). Gene expression relative to the housekeeping gene GAPDH by RT-qPCR of M2 markers (a) CCL18, (b) CD206, (c) CD163 and M1 markers (d) CCL5, (e) CCL2, (f) IL-1 $\beta$ at day 4 $(n=3)$. Original results from the authors (2021). 
nanotubes (Wang et al., 2017; Xu et al., 2019; Yu et al., 2021; Zhu et al., 2021). In contrast, titanium SLA surfaces without fine surface texture have been demonstrated to upregulate the M1 macrophage phenotype (Wang et al., 2018; Yang et al., 2021). Some studies have reported that M2 macrophage activation on $\mathrm{TiO}_{2}$ nanotube topographies is associated with enhanced spreading or elongation of macrophages on the material surface (Yu et al., 2021; Zhu et al., 2021). The upregulation of $\mathrm{M} 2$ macrophages on $\mathrm{TiO}_{2}$ nanotubes has consistently been associated with a downstream regenerative microenvironment in vitro (Wang et al., 2017; Xu et al., 2019; Yu et al., 2021; Zhu et al., 2021).

Certain microfibre polymer scaffolds with defined geometries have also been shown to induce M2 macrophage phenotype upregulation. In a study using melt-electrowritten fibre scaffolds of PCL, Tylek et al. (2020) demonstrated that scaffolds with precisely defined pore sizes are able to induce primary human

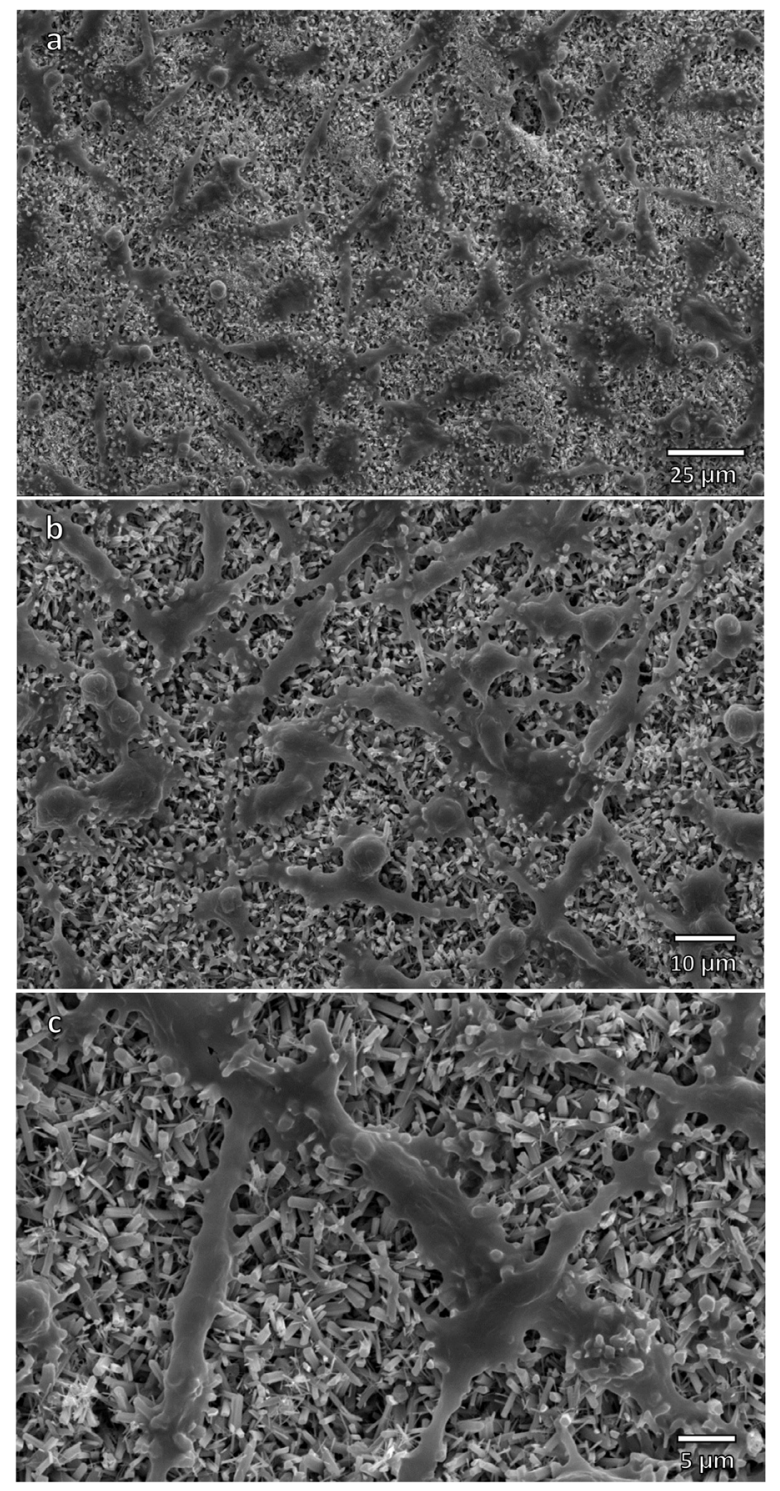

Fig. 6. SEM images of human primary macrophages cultured on $\mathbf{B C P}<\mu \mathrm{m}$ for 4 d. (a) $500 \times$, (b) $1,000 \times$, (c) 2,000× magnification. Original results from the authors (2021).
M2 macrophage activation. Other studies have shown that the diameter of PCL fibres can influence macrophage phenotype, with increasing fibre diameter resulting in M2 phenotype upregulation (Garg et al., 2013; Wang et al., 2014).

Relation between topographical features, cell shape and macrophage polarisation

The research on macrophage response to biomaterials has consistently observed that polarisation towards an M2 phenotype often is paired with a change in the morphology of the adherent macrophages. Indeed, many studies have reported enhanced spreading or elongation of macrophages in response to surface features. For example, several studies evaluating macrophage response to structured titanium surfaces have reported this behaviour (Yang et al., 2021; Yu et al., 2021; Zhu et al., 2021). This agrees with the observations made in the aforementioned in vitro studies of submicron-structured calcium phosphate using THP-1 monocytes and human primary monocytes. M2 polarised THP-1 macrophages on a needle-shaped topography had a spread-out morphology and primary human macrophages adopted an elongated morphology compared to macrophages on the material with micro-scale topography. Several groups have investigated the relationship between macrophage cell shape and phenotype. For example, several studies have demonstrated a correlation between elongated cell shape and M2 phenotype to such an extent that forcing elongation through topographical cues would induce the M2 phenotype (Luu et al, 2015; McWhorter et al., 2013; Wang et al, 2016). Other studies have reported similar observations of M2 macrophage elongation (Tylek et al., 2020; Wosik et al., 2018; Xiao et al., 2020).

Because cell shape is inextricably linked to the cytoskeleton, several studies have assessed the effect of topographical features on cytoskeletal organisation. McWhorter et al. (2013) reported that cytokine- and topography-induced elongated M2 macrophages are associated with stronger phalloidin staining intensity than untreated cells, suggesting enhanced activation of the actin cytoskeleton. Subsequently, inhibition of cytoskeletal contractility using various pharmacological agents was shown to downregulate M2 phenotype in shape-induced macrophages. Zhu et al. (2021) reported that RAW 264.7 macrophage M2 polarisation on $\mathrm{TiO}_{2}$ honeycomb topography, exhibiting enhanced cell spreading, is associated with upregulation of the Rho family of GTPases, which controls contractility of the actin cytoskeleton. Likewise, Yang et al. (2021), who studied macrophage polarisation on various titanium topographies, determined that M2 macrophage activation by surface topography is associated with enhanced ROCK expression and reduced Src expression, which are a key up-regulator and down-regulator of actin cytoskeletal tension, respectively (Lee et al., 2010). In contrast, M1 macrophages exhibit an opposite 
expression profile of ROCK and Src, suggesting a reduced activation of the actin cytoskeleton (Yang et al., 2021). Evidence indicates that topographical features of biomaterials can induce rearrangements of cytoskeletal organisation, resulting in a modulation of the macrophage cell shape. Cell shape influences downstream signalling and cell behaviour through various mechanotransduction pathways (reviewed by Haftbaradaran et al., 2020). Through this mechanism, specific structural and topographical features of biomaterials may ultimately transduce the upregulation of the M2 macrophage phenotype. Further research is necessary to identify the precise involvement of mechanotransduction in macrophage polarisation on biomaterials with structural features.

M2 macrophage upregulation is essential during bone regeneration and precedes osteoinduction by calcium phosphate in vivo

Numerous published studies have described the intricate relationship between macrophages and bone homeostasis and healing. For example, M2-like tissue-resident osteal macrophages i.e. "OsteoMacs", have been shown to play an essential role in the metabolism of bone tissue by directly regulating osteoblast survival and bone matrix deposition (Alexander et al., 2011; Raggatt et al., 2014). Besides their role in the bone tissue homeostasis, various research has indicated that macrophages are critical during the process of bone healing or regeneration. In bone repair, following an acute phase of inflammation characterised by an M1dominant macrophage population, a shift towards an M2-dominant population will occur during the later regeneration phases. For example, in a fracture healing model in mice, M1 macrophages were present until the early phase of healing (i.e. until day 3) and subsequently decreased in number while M2 macrophages were present during the ossification phase (Schlundt et al., 2018; Stefanowski et al., 2019). Moreover, upregulation of M2 macrophages in fracture calluses by in situ application of IL- 4 and IL-13 results in enhanced fracture healing (Schlundt et al., 2018). Correspondingly, a study by Zhang et al. (2018) on human patients has determined a positive correlation between the percentage of M2 macrophages in clavicle fracture calluses and the rate of bone healing.

In the context of biomaterials, augmenting the number of M2 macrophages during bone repair with various implants has been consistently linked to enhanced bone formation. For example, loading of different implant materials with IL-4, leading to M2 macrophage upregulation, results in enhanced bone defect regeneration or implant osseointegration (Hachim et al., 2017; Zhang et al., 2020; Zhao et al., 2021; Zheng et al., 2018). Moreover, Mahon et al. (2020) and Yang et al. (2021) also showed that M2 macrophage activation by materials in vitro corresponds to enhanced bone formation in vivo. Taken together, the evidence is clear that M2 macrophages are highly relevant in the context of bone healing. A study has recently shown that a pro-healing immune response precedes osteoinduction by calcium phosphates. Such results are described hereafter.

\section{A pro-healing immune response precedes osteoinduction by calcium phosphate with submicron needle-shaped topography in vivo}

After demonstrating M2 polarisation on calcium phosphate with submicron needle-shaped topography in vitro, the next step was to evaluate the innate immune response to this material in vivo. Using the same intramuscular implantation model as described above, a kinetic study was conducted on $\mathrm{BCP}_{<\mu \mathrm{m}}$ compared to conventional TCP $\mu \mathrm{m}$ to elucidate the mechanism and consequence of a prohealing innate immune reaction to submicron surface topography. At $3 \mathrm{~d}$ and 1, 3, 6 and 12 weeks after implantation, quantification of immune markers by ELISA (IL-10 for the M2 phenotype, TNF- $\alpha$ for the M1 phenotype) and bone markers by biochemical assays (ALP for osteoblasts, TRAP for osteoclasts) was performed after extraction from ex vivo implants. Histological observations were conducted for all time points to assess bone formation (methylene blue/ basic fuchsin); osteoblastic activity was assessed by ALP and osteoclastic activity by TRAP and CTSK. Following histological analysis, ectopic bone formation was observed in $\mathrm{BCP}_{<\mu \mathrm{m}}$ implants from 6 weeks onwards, with increasing amounts of bone up to week 12 (Fig. 7). Osteoid was formed in 3 out of $4 \mathrm{BCP}_{<\mu \mathrm{m}}$ samples at week $6(<1 \%$ by volume), while mineralised bone was observed in 4 out of $4 \mathrm{BCP}_{<u m}$ implants at week $12(9.4 \pm 3.7 \%)$. In contrast, only fibrous tissue formation was observed by histology in the negative control $\left(\mathrm{TCP}_{\mu \mathrm{m}}\right)$. These findings confirmed the ability of $\mathrm{BCP}_{<\mu \mathrm{m}}$ to induce ectopic bone formation. Following histological analysis of bonerelated markers, osteoclastic activity was observed from 3 weeks onwards: TRAP $^{+}$multinucleated cells with large cell bodies were detected on the surface of $\mathrm{BCP}_{<\mu \mathrm{m}}$ at the edge of the implants and in the entire implant in all samples after 6 weeks. Such cells were also $\mathrm{CTSK}^{+}$, supporting the osteoclastic nature of these multinucleated cells (Fig. 7). Moreover, a strong ALP signal was noted near the newly formed bone in $\mathrm{BCP}_{<\mu \mathrm{m}}$ at weeks 6 and 12 .

As for the analysis of immune markers, both M1 and M2 macrophage markers were detected from day 3 onwards in both implants (Fig. 8). The pro-healing activity monitored by the M2 marker IL-10 showed a consistent increase up to 6 weeks, followed by a slight decrease thereafter. At nearly every time point, IL-10 expression was significantly higher on $\mathrm{BCP}_{<\mu \mathrm{m}}$ when compared to $\mathrm{TCP}_{\mu \mathrm{m}^{\prime}}$ suggesting a favourable $\mathrm{M} 2$ polarisation response on the $\mathrm{BCP}_{<u m}$ surface. The pro-inflammatory activity monitored by the M1 marker TNF- $\alpha$ showed a consistent increase for up to 6 weeks with similar levels for $\mathrm{BCP}_{<\mu \mathrm{m}}$ and $\mathrm{TCP}_{\mu \mathrm{m}}$. 
After 12 weeks, the expression of TNF- $\alpha$ on BCP ${ }_{<\mu \mathrm{m}}$ strongly decreased on $\mathrm{TCP}_{\mu \mathrm{m}}$ but remained high on $\mathrm{BCP}_{<\mu \mathrm{m}}$.

The results of the biochemical assays on TRAP and ALP concurred with the results of the histological analysis. Significant osteoclastic TRAP activity was observed from 3 weeks onwards, gradually increasing until up to 12 weeks. TRAP expression was significantly higher on $\mathrm{BCP}_{<\mu \mathrm{m}}$ compared to $\mathrm{TCP}_{\mu \mathrm{m}}$ at every time point. Limited levels of ALP activity were detected between $3 \mathrm{~d}$ and 6 weeks following implantation. The absence of ALP staining in the histological analysis between $3 \mathrm{~d}$ and 6 weeks suggested that the early low levels of quantified ALP were mostly non-specific to bone. However, enhanced osteoblastic ALP activity was observed from 6 weeks onwards, with a substantial increase at 12 weeks for $\mathrm{BCP}_{<\mu \mathrm{m}^{\prime}}$ concurrent with the bone formation observed by histology. No signal was measured in the extraction vehicle controls, indicating the validity of these tissue response assays.

This kinetic in vivo study confirmed a pro-healing response on submicron surface structured calcium phosphate, as demonstrated by the higher M2 marker expression, which occurred prior to ectopic bone formation. In addition, the presence of osteoclasts from early time points onwards suggested that macrophages fuse together to become multinucleated osteoclasts before bone formation occurs. The study also confirmed a pro-inflammatory response immediately after implantation, as shown by the expression of the M1 marker TNF- $\alpha$. However, it should be noted that TNF- $\alpha$ expression is also a marker for osteoclasts that are derived from monocytes (Adamopoulos et al., 2006; Aeschlimann and Evans, 2004; Miron and Bosshardt, 2016).
3 weeks
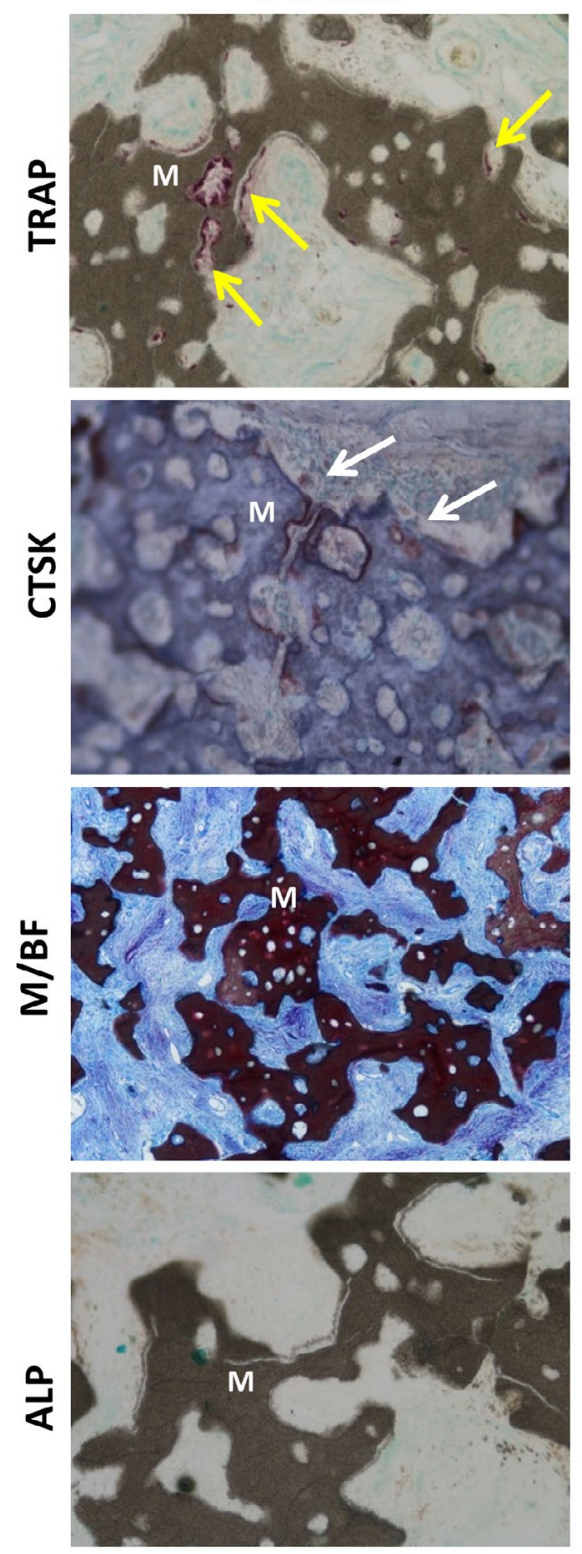

6 weeks
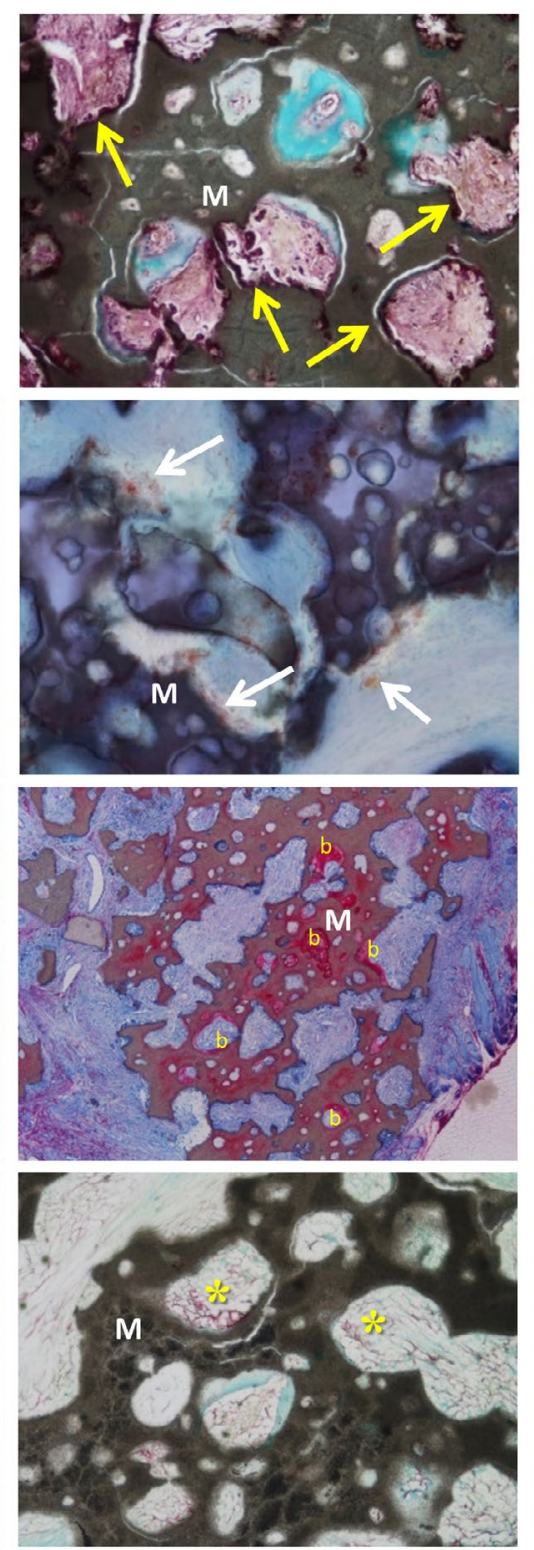

12 weeks
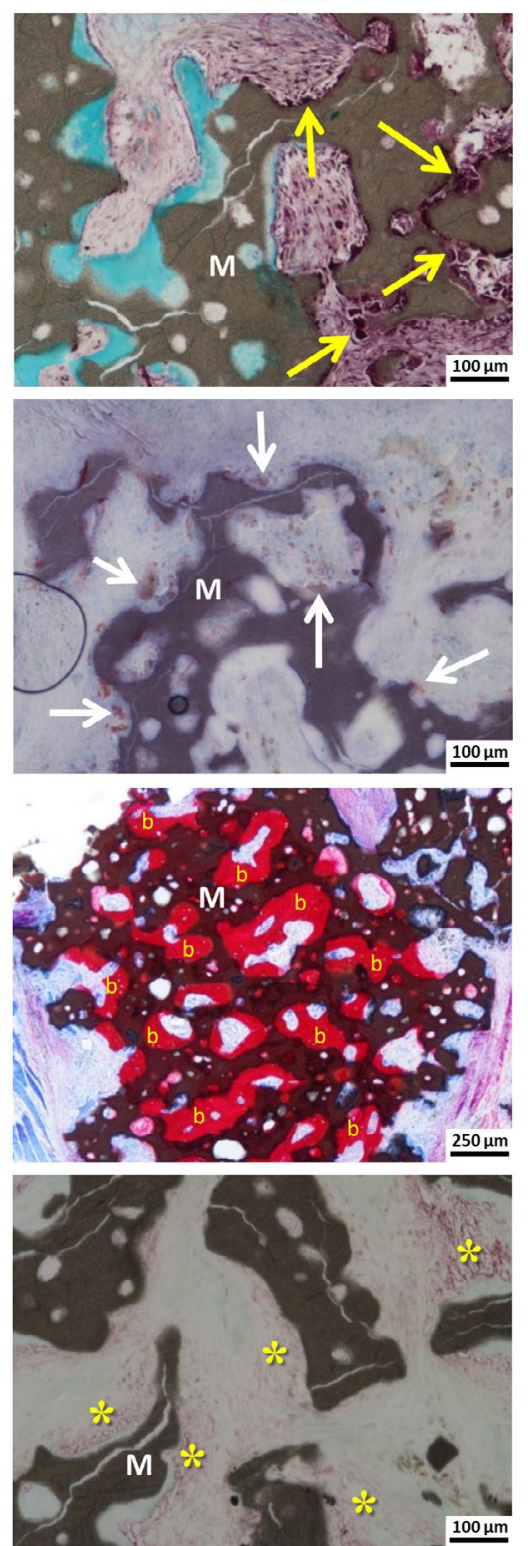

Fig. 7. Histological observations at the surface of needle-shaped $\mathrm{BCP}<\mu \mathrm{m}$ material (M). Osteoclastic activity observed from 3 weeks on by TRAP (yellow arrow) and CTSK (white arrow) samples. Bone formation observed from 6 weeks on by methylene blue/basic fuchsin (MB/F) staining (pink, b) and ALP staining (*). Original results from the authors (2021). 
Together with the evidence of osteoclastic activity on $\mathrm{BCP}_{<\mu \mathrm{m}}$ demonstrated by CTSK and TRAP, this elevated TNF- $\alpha$ level may comprise the cumulative expression from both osteoclasts and M1 proinflammatory macrophages.

Previous research has indicated the involvement of osteoclast-like multinucleated cells in osteoinduction by calcium phosphate ceramics (Davison et al., 2014a, 2014c, 2015). For example, osteoclasts differentiated from human primary monocytes survive, fuse, differentiate and resorb the substrate when cultured on osteoinductive calcium phosphate with a submicron surface structure. In contrast, calcium phosphate with a micron-structured surface attenuates osteoclast survival, fusion and differentiation (Davison et al., 2014b). Furthermore, it has been suggested that osteoclast-like, multinucleated cells, which are commonly observed around bone biomaterials, can have an M2-like macrophage phenotype and function, based on the expression of M2 markers (Miron and Bosshardt, 2016). More research is needed to identify the exact profile and function of these cells.

\section{A pro-healing response by calcium phosphate with submicron topography leads to reliable spinal fusion outcomes}

Spinal fusion equivalent to "gold standard" and superior to conventional graft materials

The relevance of osteoinductive materials has been repeatedly demonstrated in several challenging preclinical implantation models (van Dijk et al., $2018,2019,2020)$. In the more clinically relevant PLF indication, the performance of $\mathrm{BCP}_{<\mu \mathrm{m}}$ with submicron needle-shaped features was found equivalent to the gold standard autograft as a graft extender in a validated rabbit PLF model (Boden et al., 1995; van Dijk et al., 2019) and as a standalone graft in a sheep PLF model (van Dijk et al., 2018). In sheep, $\mathrm{BCP}_{<\mu \mathrm{m}}$ implanted as stand-alone for 6,12 and 26 weeks demonstrated rapid and reliable fusion. Only 6 weeks after implantation, new bone was formed in the centre of the fusion mass (distant from the host bone) and not solely in the vicinity of the host bone. Histology demonstrated bone bridging and
TNF- $\alpha$

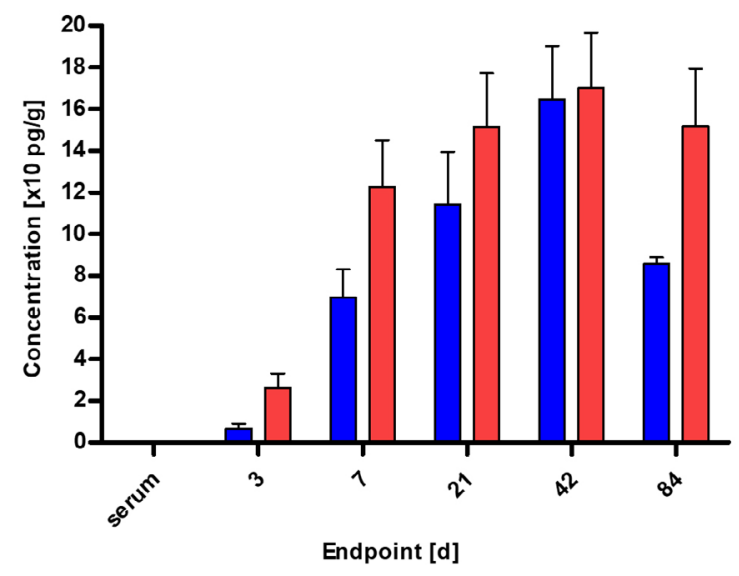

TRAP

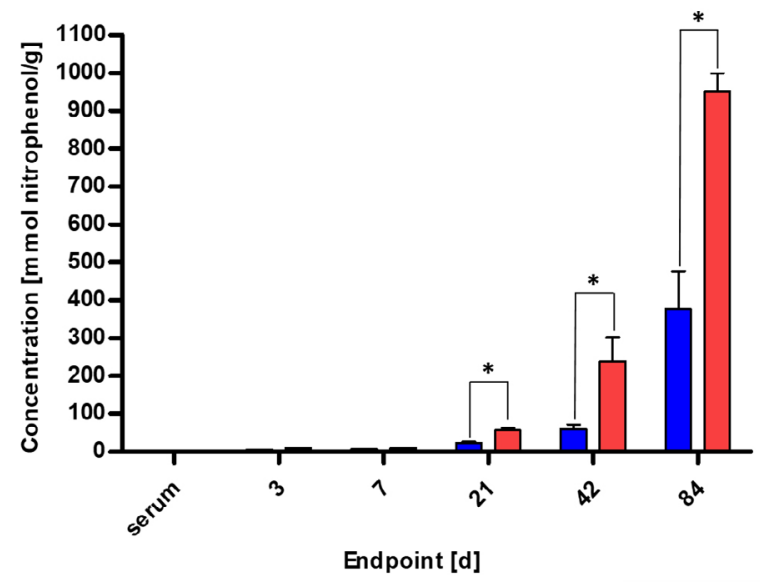

IL-10

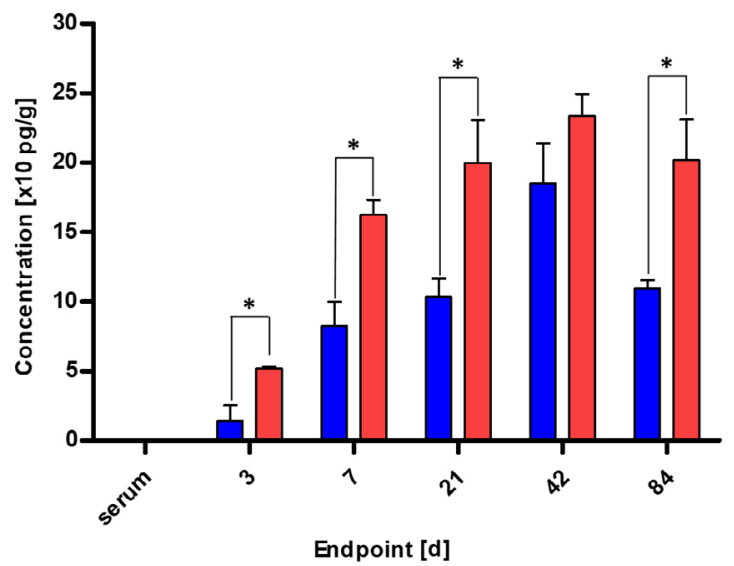

ALP

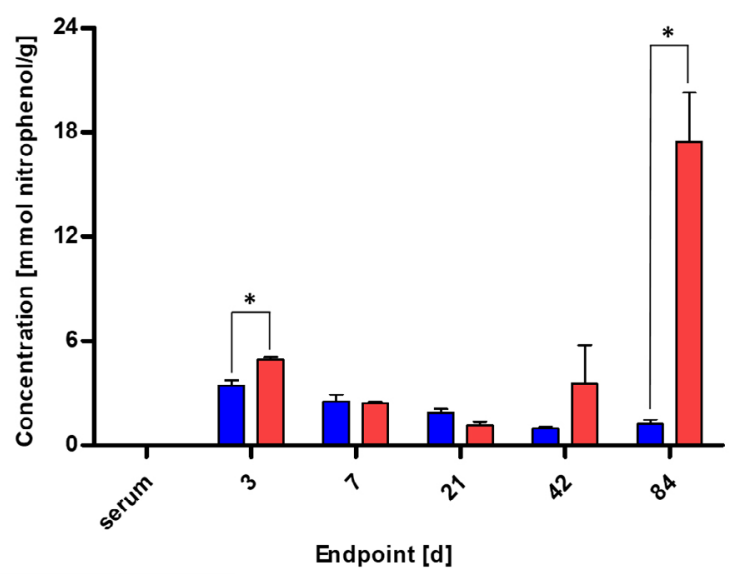

Fig. 8. Biochemical assays of TNF- $\alpha$, IL-10, TRAP and ALP extracted from ex vivo implants collected after $3 \mathrm{~d}, 1,3,6$ and 12 weeks. An extract from serum was used as a control. Significant differences were shown only between materials at each endpoint with ${ }^{*} p<0.05$. Red: $\mathrm{BCP}_{<\mu \mathrm{m}^{\prime}}$ blue: $\mathrm{TCP}_{\mu \mathrm{m}}$. Original results from the authors (2021). 
$92 \%$ to $100 \%$ fusion at 12 and 26 weeks, respectively. Fusion masses showed evidence of a pseudo-cortex, as well as bone maturation and graft integration (Fig. 9). Additional assessment methods used to score fusion, that is, manual palpation, mechanical testing and radiographical examination following the Lenke scale, were in agreement with histology and the results were equivalent to the autograft used as a positive control (Lenke et al., 1992; van Dijk et al., 2018).
The enhanced fusion performance by $\mathrm{BCP}_{<\mu \mathrm{m}}$ was confirmed when compared to conventional bone graft materials, i.e. a $\mathrm{BG}_{\mu \mathrm{m}}$ material and a $\mathrm{TCP}_{\mu \mathrm{m}}$ with $\mathrm{BG}_{\mu \mathrm{m}}$ adjunct (TCP ${ }_{\mu \mathrm{m}} / \mathrm{BG}_{\mu \mathrm{m}}$ ), as well as the "gold standard" autograft in the same sheep PLF model (van Dijk et al. 2020). By $\mu \mathrm{CT}$, only $\mathrm{BCP}_{<\mu \mathrm{m}}$ and autograft maintained an appropriate bilateral fusion mass volume of respectively $9.6 \pm 0.4 \mathrm{~cm}^{3}$ and $5.7 \pm 1.6 \mathrm{~cm}^{3}$. Significantly lower fusion mass volumes were observed for $\mathrm{BG}_{\mu \mathrm{m}}\left(3.0 \pm 1.1 \mathrm{~cm}^{3}\right)$ and $\mathrm{TCP}{ }_{\mu \mathrm{m}} / \mathrm{BG}_{\mu \mathrm{m}}$
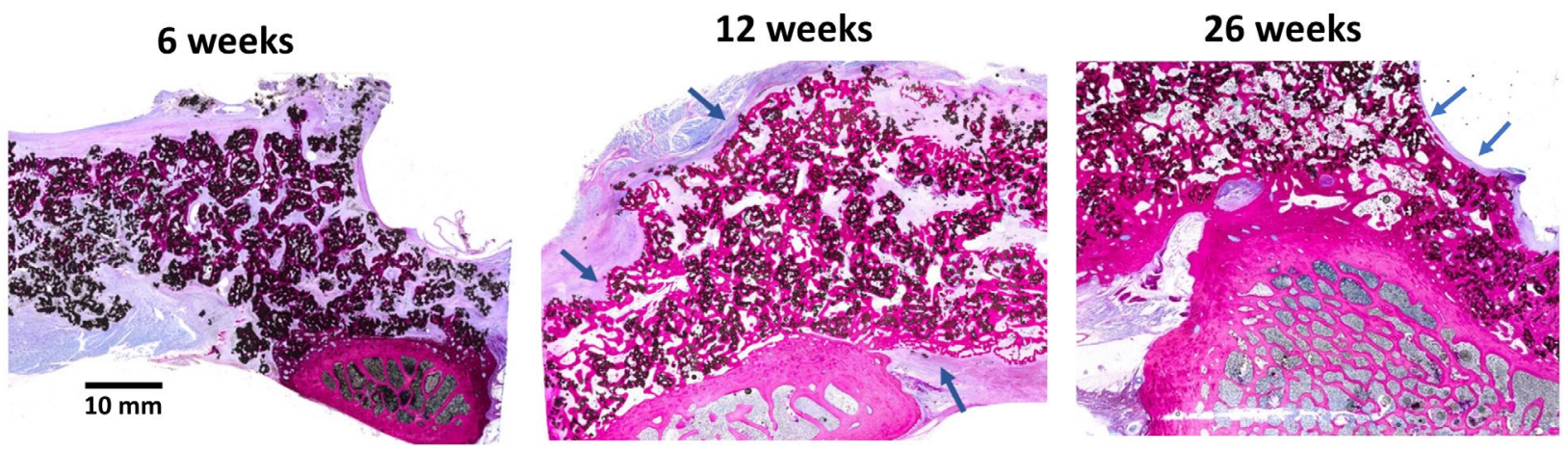

Fig. 9. Histology of $\mathrm{BCP}<\mu \mathrm{m}$ as bone graft in a sheep PLF model. The images show bone formation and neocortex formation (blue arrow) in the fusion mass at 6, 12 and 26 weeks post-implantation. Adapted from van Dijk et al. $(2018,2020)$.

a

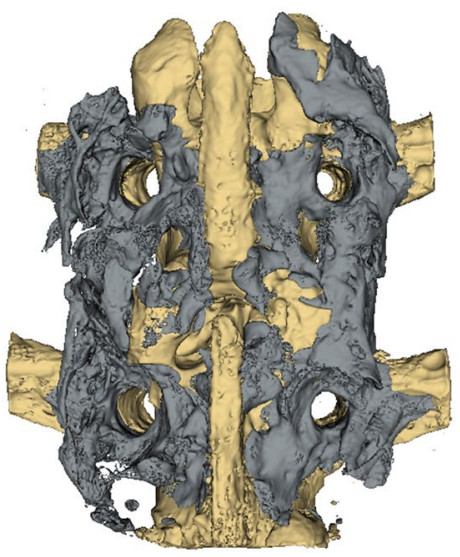

c

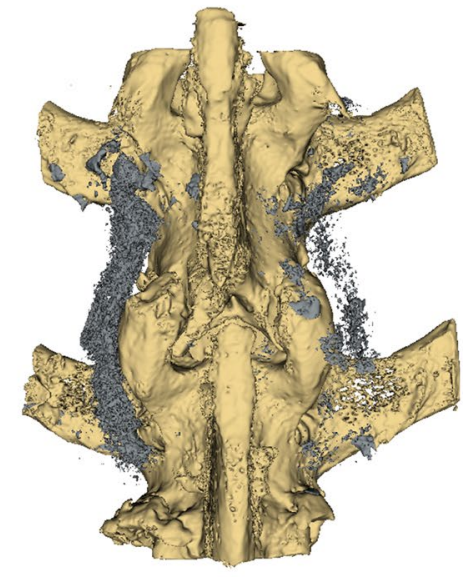

b

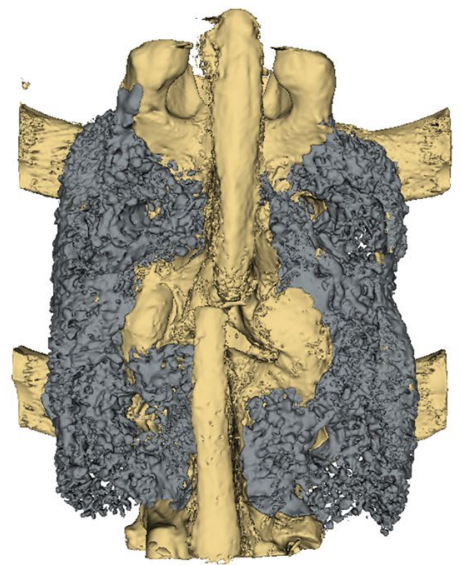

d

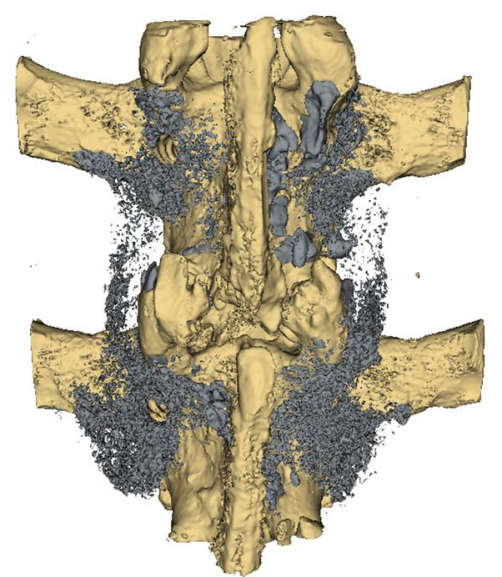

Fig. 10. 3D $\mu \mathrm{C}$ T reconstructions of spinal levels treated with autograft, $\mathrm{BCP}_{<\mu \mathrm{m}^{\prime}} \mathrm{BG}_{\mu \mathrm{m}}$ and $\mathrm{TCP} \mathrm{P}_{\mu \mathrm{m}} / \mathrm{BG}_{\mu \mathrm{m}}$. The panels present (a) autograft, (b) $\mathrm{BCP}_{<\mu \mathrm{m}^{\prime}}$ (c) $\mathrm{BG}_{\mu \mathrm{m}}$ and (d) $\mathrm{TCP}_{\mu \mathrm{m}} / \mathrm{BG}_{\mu \mathrm{m}}$. The host spinal bone (offwhite) and fusion mass (grey) including (new) bone and residual implant material are shown as separate segmentations. Adapted from van Dijk et al. (2020). 

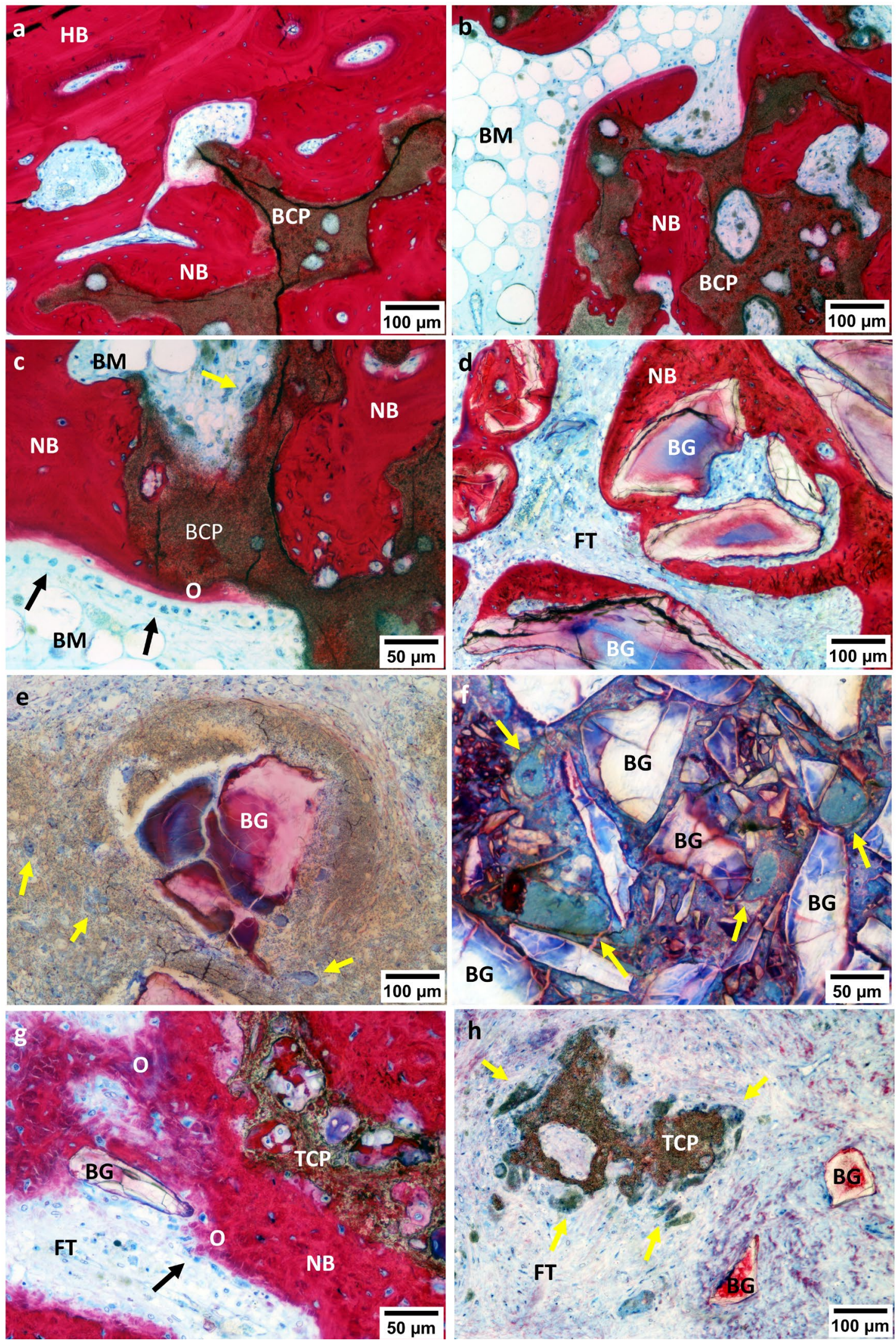

Fig. 11. Histology of bone grafts at the treated spinal levels. Representative micrographs from histological sections of the spinal levels treated with (a-c) $\mathrm{BCP}_{<\mu \mathrm{m}^{\prime}}(\mathbf{d}-\mathbf{f}) \mathrm{BG}_{\mu \mathrm{m}}$ and $(\mathbf{g}, \mathbf{h}) \mathrm{TCP}{ }_{\mu \mathrm{m}} / \mathrm{BG}_{\mu \mathrm{m}}$. Micrographs were obtained from regions near $(\mathbf{a}, \mathbf{d}, \mathbf{g})$ the host transverse process and $(\mathbf{b}, \mathbf{c}, \mathbf{e}, \mathbf{f}, \mathbf{h})$ the intertransverse central region. High magnification images show cellular processes observed near the graft materials, including osteoblasts (c, $\mathbf{g}$ - black arrows) depositing osteoid and cell-mediated resorption of materials by multinucleated cells $(\mathbf{c}, \mathbf{h}$ - yellow arrows). Inflammatory foreign body reaction was observed in BG $\mu \mathrm{m}$ specimens, as evidenced by encapsulation of material and large numbers of lymphocytes and foreign body giant cells (i, yellow arrows). HB: host bone; NB: new bone; BM: bone marrow; O: osteoid; FT: fibrous tissue. Adapted from van Dijk et al. (2020). 
$\left(2.4 \pm 1.0 \mathrm{~cm}^{3}\right)$ (Fig. 10). Correspondingly, histology revealed abundant bone tissue in direct contact with $\mathrm{BCP}_{<\mu \mathrm{m}}$ throughout the inter-transverse space. A large area of $\mathrm{BCP}_{<\mu \mathrm{m}}$ graft was integrated into newly formed trabecular bone with lamellar morphology and bone marrow spaces (Fig. 11a-c). Osteoblasts lining regions, osteoclasts and osteocytes were observed throughout the specimens (Fig. 11c). Multinucleated cells were observed resorbing the material on the surface that was not covered by bone (Fig. 11c). Histology on the $\mathrm{TCP}_{\mu \mathrm{m}} / \mathrm{BG}_{\mu \mathrm{m}}$ and $\mathrm{BG}_{\mu \mathrm{m}}$ groups confirmed the absence of bone tissue and significant graft resorption through the implant site. Bone formation was very minimal and limited at the vicinity of host bone (Fig. 11d,g). Throughout the implant site, residual $\mathrm{BG}_{u m}$ particles were mostly encapsulated in fibrous tissue or granulomatous inflammatory tissue with the presence of lymphocytes and foreign body giant cells in 5 out of 6 specimens (Fig. 11e,f). Moreover, 3 out of $6 \mathrm{BG}_{\mu \mathrm{m}}$ specimens contained dense regions of particles of variable dimensions, which were revealed to be areas of severely fragmented material and evidence of foreign body reaction upon further inspection (Fig. 11f). In the $\mathrm{TCP}_{\mu \mathrm{m}} / \mathrm{BG}_{\mu \mathrm{m}}$ implantation sites, $\mathrm{TCP}_{\mu \mathrm{m}}$ particles were commonly observed in the process of disintegration due to cell-mediated resorption (Fig. 11h). The cellular and tissue reaction on the 3 different bone grafts showed significant differences, emphasising the relevance of needle-shaped surface features of $\mathrm{BCP}_{<\mu \mathrm{m}}$

The different immune responses for these 3 graft materials in vivo were evident and led to a significantly different fusion performance. On the one hand, the abundant fibrous encapsulation, granulomatous inflammation and graft resorption observed on the $\mathrm{TCP}{ }_{\mu \mathrm{m}} / \mathrm{BG}_{\mu \mathrm{m}}$ and $\mathrm{BG}_{\mu \mathrm{m}}$ groups were characteristic of a pro-inflammatory reaction, which in turn resulted in poor bone formation and did not achieve fusion. On the other hand, material remodelling by multinucleated cells combined with new bone formation in direct contact with the $\mathrm{BCP}_{4 \mathrm{~m}}$ material suggests a pro-healing reaction, resulting in early bone formation throughout the inter-transverse space favourable for fusion. The late endpoints and the lack of other histological immunostaining prevent any further insight on the nature of innate immunological reaction in vivo. However, these striking differences in foreign body reaction and bone healing, combined with the above in vitro results on the same materials, suggest a unique pro-healing mechanism orchestrated by the needle-shaped topographical features.

\section{Clinically reliable spine fusion}

The performance of submicron needle-shaped feature bone grafts has been validated clinically in a retrospective cohort study of 77 lumbar and cervical reconstruction patients receiving interbody and posterolateral spinal fusions (Level IV study by Poelstra et al. unpublished work). The bone graft $\mathrm{BCP}_{<\mu \mathrm{m}}$ was mixed with acellular allograft and BMA for the lumbar region and with local autograft for the cervical region. Radiographic evaluations and clinical outcomes for fusion were assessed at multiple intervals after surgery.

The lumbar group consisted of 24 females and 28 males. This cohort included posterior, lateral or anterior lumbar interbody fusions with or without posterior instrumented fusions. The bone graft $\mathrm{BCP}_{<\mu \mathrm{m}}$ was mixed with acellular allograft and BMA. The procedures included 22 one-level (42.3\%), 19 two-level (36.5 \%), 7 three-level (13.5 \%) and 4 fourlevel $(7.7 \%)$ procedures for a total of 97 treated levels. The average duration of follow-up was 7.5 months (6.0-11.8 months). The mean age was 60.9 years (28-83 years), with a mean BMI of 29.6 (20.6-46.5). The modified Prolo scores (0-20 scale) improved significantly overall from an average of 11.0 preoperatively to 16.1 postoperatively $(68.3 \%)$ in 51 out of 52 patients. Improvement in pain and function demonstrated successful outcomes following surgery, as Prolo scores were reported as excellent $(47.1 \%)$, good $(49.0 \%)$ or fair $(3.9 \%)$, with each reporting $\geq 3$ points of improvement in the post-operative score compared to baseline scores. Successful fusion was confirmed 6 months postoperatively in 42 out of 52 patients $(80.7 \%)$ and 12 months postoperatively in 49 out of 52 patients (94.2\%). Radiographic evidence of successful fusion was seen by 12 months in 94 out of 97 levels (96.9\%). A breakdown for this cohort is provided in Table 1. Pseudarthrosis was only observed in 3 out of 97 levels (3.1\%). Overall, the lumbar fusion cohort achieved a near $97 \%$ (94 out of 97 levels) fusion rate with $\mathrm{BCP}_{<\mu \mathrm{m}^{\prime}}$ which compared favourably to a recent meta-analysis using the same surgical technique (Li et al., 2017). Likewise, radiographic fusions through 3D-printed titanium cages in the cervical spine were achieved in 75 out of 80 levels (93.8\%), of which 31 out of 32 levels $(96.9 \%)$ fused in one- to three-level reconstructions and 20 out of 24 levels (83.3 \%) fused after four-level reconstructions, despite multiple comorbidities in the latter cohort. None of these patients required revision surgery within 18 months from the index operation. Overall, cervical fusion was reached in 21 out of 25 patients with excellent clinical outcomes, which compared favourably with a recent publication by Arnold et al. (2016).

The cervical group consisted of 9 males and 16 females. The procedures included posterior fusions and anterior-posterior combined reconstructions. The submicron surface $\mathrm{BCP}_{<\mu \mathrm{m}}$ bone graft material was mixed with autograft placed either inside of the interbody cages or posterolateral, adjacent to the lateral-mass and pedicle screws. The average length of follow-up for the entire cervical cohort was 6.4 months (3-11 months). The mean age was 61.2 years (33-80 years), with a mean BMI of 29.5 (18.7-46.4). Modified Prolo average scores (0-20 scale) improved overall from 10.8 preoperatively to 16.0 postoperatively $(68.7 \%)$ in 23 out of 25 patients who reported proper follow-up. Prolo scores 
Table 1. Results from 52 lumbar fusion patients. Solid arthrodesis was noted in 94 out of 97 levels $(96.9 \%)$ in 49 out of 52 patients after 12 months. Comorbidities prevalent $>30 \%$ in this cohort included: anxiety, depression, diabetes, hyperlipidaemia, gastro-oesophageal reflux disease, sleep apnoea, morbid obesity and smoking.

\begin{tabular}{|l|c|c|}
\hline \multicolumn{3}{|c|}{ Lumbar group ( $n=52)$} \\
\hline Mean age (28 - 83 years) & 60.9 & \\
\hline Female & 44 & $46.2 \%$ \\
\hline Male & 33 & $53.8 \%$ \\
\hline Mean BMI (20.6-46.5) Procedures \\
\hline \multicolumn{3}{|c|}{29.6} \\
\hline ALIF + posterior fusion & 23 & $44.2 \%$ \\
\hline Lateral + posterior fusion & 12 & $23.1 \%$ \\
\hline ALIF only & 5 & $9.6 \%$ \\
\hline Lateral only & 9 & $17.3 \%$ \\
\hline Posterior only & 3 & $5.8 \%$ \\
\hline \multicolumn{3}{|c|}{ Fusion levels per procedure } \\
\hline 1 level & 22 & $42.3 \%$ \\
\hline 2 levels & 19 & $36.5 \%$ \\
\hline 3 levels & 7 & $13.5 \%$ \\
\hline 4 levels & 4 & $7.7 \%$ \\
\hline \multicolumn{2}{|c|}{ Fusion results for all levels } \\
\hline Fusion success at 6 months & $82 / 97$ & $84.5 \%$ \\
\hline Fusion success at 12 months & $94 / 97$ & $96.9 \%$ \\
\hline Pseudarthrosis at 12 months & $3 / 97$ & $3.1 \%$ \\
\hline
\end{tabular}

demonstrated positive outcomes with categories reported as excellent $(61 \%)$, good $(35 \%)$ or fair $(4 \%)$. Each reported at least a 3 points post-operative score improvement for pain and function. Fusion status was monitored using flexion/extension films and $\mu C T$-scan sagittal/coronal reconstructions as early as 3 months and as late as 12 months postoperatively, when indicated. Successful fusion was achieved by 6 months in 53 out of 80 levels (66\%). At 12 months, the remaining levels fused, except for 5 proven pseudoarthroses in 4 patients that all occurred in 1 three-level and 3 four-level anterior standalone reconstructions fitted with the titanium 3D printed cages and static locking plates. At 12 months, successful fusion was observed in 75 out of 80 levels (93.8\%), with radiographic evidence (Table 2). Fusion was achieved in 18 out of 18 PCF levels, 4 out of 4 corpectomy surfaces and 51 out of 56 ACDF standalone procedure levels (91.1\%). All single and two-level ACDF levels fused solid (14 out of 14). In the three-level cases, $94.5 \%$ fused (17 out of 18), whereas $83.3 \%$ of the four-level ACDF levels fused without posterior hardware (20 out of 24). All anterior-posterior reconstructions of five-levels or greater fused solidly. The confirmed pseudarthrosis cases remained clinically asymptomatic more than 12 months after surgery and each of these 4 patients involved one or more comorbidities known to negatively affect fusion success, including two
Table 2. Results from 25 cervical fusion patients. Solid arthrodesis was noted in 75 out of 80 levels in 21 out of 25 patients after 12 months; one-, two- and three-level ACDF cases fused in 31 out of 32 cases (96.8 \%). Co-morbidities prevalent $>30 \%$ in this cohort included: hypertension, gastro-oesophageal reflux disease, diabetes I or II, anxiety, depression, dyslipidaemia, generalised osteo arthritis, obesity and smoking.

\begin{tabular}{|l|c|c|}
\hline \multicolumn{3}{|c|}{ Cervical group ( $n=25)$} \\
\hline Mean age (33 - 80 years) & 61.2 & \\
\hline Female & 16 & $64.0 \%$ \\
\hline Male & 9 & $36.0 \%$ \\
\hline Mean BMI (18.7 - 46.4) & 29.5 & \\
\hline \multicolumn{3}{|c|}{ Procedures } \\
\hline $\begin{array}{l}\text { Anterior only } \\
\text { (ACDF = 19/corpectomy }=2)\end{array}$ & 21 & $84.0 \%$ \\
\hline Posterior only (PCF) & 1 & $4.0 \%$ \\
\hline ACDF + PCF & 2 & $8.0 \%$ \\
\hline \multicolumn{2}{|c|}{ Fusion results per procedure $(n=80)$} \\
\hline PCF & $20 / 20$ & $100 \%$ \\
\hline Corpectomy surfaces & $4 / 4$ & $100 \%$ \\
\hline ACDF total & $51 / 56$ & $91.1 \%$ \\
\hline $1+2$ levels & $14 / 14$ & $100 \%$ \\
\hline 3 levels & $17 / 18$ & $94.4 \%$ \\
\hline 4 levels & $20 / 24$ & $83.3 \%$ \\
\hline \multicolumn{2}{|c|}{ Fusion results for all levels } \\
\hline Fusion success at 6 months & $53 / 80$ & $66.3 \%$ \\
\hline Fusion success at 12 months & $75 / 80$ & $93.8 \%$ \\
\hline Pseudarthrosis at 12 months & $5 / 80$ & $6.3 \%$ \\
\hline
\end{tabular}

smokers (Table 2). None of them required additional surgical procedures to date $(18$ months postoperatively). There were no instances of infection, product-related adverse events or hardware failures in both lumbar and cervical groups.

These data demonstrated that this calcium phosphate bone graft material with submicron surface topography could deliver solid, stable and reliable fusions in real-world clinical applications, with a pseudo-arthrodesis rate comparable to autograft in both cervical and lumbar interbody applications (Levin et al., 2018; Li et al., 2017; McAfee et al., 2012; Shao et al., 2017). Future studies with longer-term follow-up and patient-reported outcomes are most certainly indicated, while level I prospective randomised studies (Web ref. 1) and additional level IV clinical investigations are currently underway (Web ref. 2).

\section{Conclusion}

The present review describes the sensitivity of macrophages to material surface features and the relevance thereof to bone regeneration. Materials with defined topographical features, such as a 
submicron topography, upregulate macrophages with an anti-inflammatory, pro-healing phenotype in vitro and in vivo. Osteoinductive calcium phosphates with submicron-scale needle-shaped surface features favourably modulate the innate immune response by these means, leading to accelerated and enhanced bone regeneration. Within the first days after implantation, a submicron topography induces a pro-healing immune response that favours initial osteoclastic activity, followed by osteoblastic activity leading to bone formation. This mechanism of material-directed bone formation was translated into reliable spinal fusion outcomes in relevant pre-clinical models and human patients. Design of bone graft materials with specific surface features to modulate the healing response is feasible and can evidently improve healing outcomes. Control of the innate immune response appears to be a key factor in the efficacy of biomaterials.

\section{Acknowledgements}

The authors would like to thank Dr Rongquan Duan, Devlina Ghosh, Dr Lizette Utomo and Dr Debby Gawlitta for their scientific contribution to this review. This work was supported by Kuros Biosciences BV and the European Union's Horizon 2020 research and innovation program (grant agreements numbers 674282 and 874790).

\section{References}

Adamopoulos IE, Sabokbar A, Wordsworth BP, Carr A, Ferguson DJ, Athanasou NA (2006) Synovial fluid macrophages are capable of osteoclast formation and resorption. J Pathol 208: 35-43.

Aeschlimann D, Evans B (2004) The vital osteoclast: how is it regulated? Cell Death Differ 11: S5-S7.

Alexander KA, Chang MK, Maylin ER, Kohler T, Müller R, Wu AC, Van Rooijen N, Sweet MJ, Hume DA, Raggatt LJ, Pettit AR (2011) Osteal macrophages promote in vivo intramembranous bone healing in a mouse tibial injury model. J Bone Miner Res 26: 15171532.

Arnold PM, Sasso RC, Janssen ME, Fehlings MG, Smucker JD, Vaccaro AR, Heary RF, Patel AI, Goulet B, Kalfas IH, Kopjar B (2016) Efficacy of i-factor bone graft versus autograft in anterior cervical discectomy and fusion results of the prospective, randomized, single-blinded food and drug administration investigational device exemption study. Spine (Phila Pa 1976) 41: 1075-1083.

Barradas AMC, Yuan H, van Blitterswijk CA, Habibovic P (2011) Osteoinductive biomaterials: current knowledge of properties, experimental models and biological mechanisms. Eur Cell Mater 21: 407-429.
Boden SD, Schimandle JH, Hutton WC (1995) An experimental lumbar intertransverse process spinal fusion model: radiographic, histologic, and biomechanical healing characteristics. Spine (Phila Pa 1976) 20: 412-420.

Bota PCS, Collie AMB, Puolakkainen P, Vernon RB, Sage EH, Ratner BD, Stayton PS (2010) Biomaterial topography alters healing in vivo and monocyte/ macrophage activation in vitro. J Biomed Mater Res A 95: 649-657.

Brown BN, Ratner BD, Goodman SB, Amar S, Badylak SF (2012) Macrophage polarization: an opportunity for improved outcomes in biomaterials and regenerative medicine. Biomaterials 33: 37923802.

Buchacher T, Ohradanova-Repic A, Stockinger H, Fischer MB, Weber V (2015) M2 polarization of human macrophages favors survival of the intracellular pathogen chlamydia pneumoniae. PLoS One 10: e0143593. DOI: 10.1371/journal.pone.0143593.

Chen Z, Klein T, Murray RZ, Crawford R, Chang J, Wu C, Xiao Y (2016) Osteoimmunomodulation for the development of advanced bone biomaterials. Mater Today 19: 304-321.

Davenport Huyer L, Pascual-Gil S, Wang Y, Mandla S, Yee B, Radisic M (2020) Advanced strategies for modulation of the material-macrophage interface. Adv Funct Mater 30: 1909331. DOI: 10.1002/ adfm.201909331.

Davison NL, Gamblin AL, Layrolle P, Yuan H, de Bruijn JD, Barrère-de Groot F (2014a) Liposomal clodronate inhibition of osteoclastogenesis and osteoinduction by submicrostructured beta-tricalcium phosphate. Biomaterials 35: 5088-5097.

Davison NL, ten Harkel B, Schoenmaker T, Luo X, Yuan H, Everts V, Barrère-de Groot F, de Bruijn JD (2014b) Osteoclast resorption of beta-tricalcium phosphate controlled by surface architecture. Biomaterials 35: 7441-7451.

Davison NL, Luo X, Schoenmaker T, Everts V, Yuan H, Barrère-de Groot F, de Bruijn JD (2014c) Submicron-scale surface architecture of tricalcium phosphate directs osteogenesis in vitro and in vivo. Eur Cells Mater 27: 281-297.

Davison NL, Su J, Yuan H, van den Beucken JJJP, de Bruijn JD, de Groot FB (2015) Influence of surface microstructure and chemistry on osteoinduction and osteoclastogenesis by biphasic calcium phosphate discs. Eur Cells Mater 29: 314-329.

Dorozhkin SV (2013) Calcium orthophosphatebased bioceramics. Materials (Basel) 6: 3840-3942.

Duan R, van Dijk LA, Barbieri D, de Groot F, Yuan H, de Bruijn JD (2019) Accelerated bone formation by biphasic calcium phosphate with a novel sub-micron surface topography. Eur Cell Mater 37: 60-73.

Garg K, Pullen NA, Oskeritzian CA, Ryan JJ, Bowlin GL (2013) Macrophage functional polarization (M1/M2) in response to varying fiber and pore dimensions of electrospun scaffolds. Biomaterials 34: 4439-4451. 
Habibovic P, Yuan H, van den Doel M, Sees TM, van Blitterswijk CA, de Groot K (2006) Relevance of osteoinductive biomaterials in critical-sized orthotopic defect. J Orthop Res 24: 867-876.

Hachim D, LoPresti ST, Yates CC, Brown BN (2017) Shifts in macrophage phenotype at the biomaterial interface via IL-4 eluting coatings are associated with improved implant integration. Biomaterials 112: 95107.

Haftbaradaran Esfahani P, Knöll R (2020) Cell shape: effects on gene expression and signaling. Biophys Rev 12: 895-901.

Heughebaert M, LeGeros RZ, Gineste M, Guilhem A, Bonel G (1988) Physicochemical characterization of deposits associated with HA ceramics implanted in nonosseous sites. J Biomed Mater Res 22: 257-268.

Hotchkiss KM, Reddy GB, Hyzy SL, Schwartz Z, Boyan BD, Olivares-Navarrete R (2016) Titanium surface characteristics, including topography and wettability, alter macrophage activation. Acta Biomater 31: 425-434.

Hsu WK, Nickoli MS, Wang JC, Lieberman JR, An HS, Yoon ST, Youssef JA, Brodke DS, McCullough CM (2012) Improving the clinical evidence of bone graft substitute technology in lumbar spine surgery. Glob Spine J 2: 239-248.

Jablonská E, Horkavcová D, Rohanová D, Brauer DS (2020) A review of in vitro cell culture testing methods for bioactive glasses and other biomaterials for hard tissue regeneration. J Mater Chem B 8: 1094110953.

Klein C, de Groot K, Chen W, Li Y, Zhang X (1994) Osseous substance formation induced in porous calcium phosphate ceramics in soft tissues. Biomaterials 15: 31-34.

Klopfleisch R (2016) Macrophage reaction against biomaterials in the mouse model - phenotypes, functions and markers. Acta Biomater 43: 3-13.

Klopfleisch R, Jung F (2017) The pathology of the foreign body reaction against biomaterials. J Biomed Mater Res A 105: 927-940.

Kumar M, Coburn J, Kaplan DL, Mandal BB (2016) Immuno-Informed 3D silk biomaterials for tailoring biological responses. ACS Appl Mater Interfaces 8: 29310-29322.

Lebre F, Sridharan R, Sawkins MJ, Kelly DJ, O'Brien FJ, Lavelle EC (2017) The shape and size of hydroxyapatite particles dictate inflammatory responses following implantation. Sci Rep 7: 1-13.

Lee HH, Tien SC, Jou TS, Chang YC, Jhong JG, Chang ZF (2010) Src-dependent phosphorylation of ROCK participates in regulation of focal adhesion dynamics. J Cell Sci 123: 3368-3377.

Lenke LG, Bridwell KH, Bullis D, Betz RR, Baldus C, Schoenecker PL (1992) Results of in situ fusion for isthmic spondylolisthesis. J Spinal Disord 5: 433-442.

Levin JM, Tanenbaum JE, Steinmetz MP, Mroz TE, Overley SC (2018) Posterolateral fusion (PLF) versus transforaminal lumbar interbody fusion (TLIF) for spondylolisthesis: a systematic review and metaanalysis. Spine J 18: 1088-1098.
Li C, Yang L, Ren X, Lin M, Jiang X, Shen D, Xu T, Ren J, Huang L, Qing W, Zheng J, Mu Y (2019) Groove structure of porous hydroxyapatite scaffolds (HAS) modulates immune environment via regulating macrophages and subsequently enhances osteogenesis. J Biol Inorg Chem 24: 733-745.

Li JXJ, Phan K, Mobbs R (2017) Oblique lumbar interbody fusion: technical aspects, operative outcomes, and complications. World Neurosurg 98: 113-123.

Linares J, Fernández AB, Feito MJ, Matesanz MC, Sánchez-Salcedo S, Arcos D, Vallet-Regí M, Rojo JM, Portolés MT (2016) Effects of nanocrystalline hydroxyapatites on macrophage polarization. J Mater Chem B 4: 1951-1959.

Luu TU, Gott SC, Woo BWK, Rao MP, Liu WF (2015) Micro- and nanopatterned topographical cues for regulating macrophage cell shape and phenotype. ACS Appl Mater Interfaces 7: 28665-28672.

Mabud T, Norden J, Veeravagu A, Swinney C, Cole T, McCutcheon BA, Ratliff J (2017) Complications, readmissions, and revisions for spine procedures performed by orthopedic surgeons versus neurosurgeons. Clin Spine Surg 30: E1376-E1381.

Mahon OR, Browe DC, Gonzalez-Fernandez T, Pitacco P, Whelan IT, Von Euw S, Hobbs C, Nicolosi V, Cunningham KT, Mills KHG, Kelly DJ, Dunne A (2020) Nano-particle mediated M2 macrophage polarization enhances bone formation and MSC osteogenesis in an IL-10 dependent manner. Biomaterials 239: 119833. DOI: 10.1016/j. biomaterials.2020.119833.

McAfee PC, Reah C, Gilder K, Eisermann L, Cunningham B (2012) A meta-analysis of comparative outcomes following cervical arthroplasty or anterior cervical fusion: results from 4 prospective multicenter randomized clinical trials and up to 1226 patients. Spine (Phila Pa 1976) 37: 943-952.

McWhorter FY, Wang T, Nguyen P, Chung T, Liu WF (2013) Modulation of macrophage phenotype by cell shape. Proc Natl Acad Sci U S A 110: 17253-17258.

Millennium Research Group (2016) Orthopedic Biomaterials. Medtech 360. Market Analysis. US. 2017. Toronto.

Miron RJ, Bosshardt DD (2016) OsteoMacs: key players around bone biomaterials. Biomaterials 82: 1-19.

Morris MT, Tarpada SP, Cho W (2018) Bone graft materials for posterolateral fusion made simple: a systematic review. Eur Spine J 27: 1856-1867.

Raggatt LJ, Wullschleger ME, Alexander KA, Wu ACK, Millard SM, Kaur S, Maugham ML, Gregory LS, Steck R, Pettit AR (2014) Fracture healing via periosteal callus formation requires macrophages for both initiation and progression of early endochondral ossification. Am J Pathol 184: 3192-3204.

Reeves ARD, Spiller KL, Freytes DO, VunjakNovakovic G, Kaplan DL (2015) Controlled release of cytokines using silk-biomaterials for macrophage polarization. Biomaterials 73: 272-283. 
Ripamonti U, Roden LC, Ferretti C, Klar RM (2011) Biomimetic matrices self-initiating the induction of bone formation. J Craniofac Surg 22: 1859-1870.

Scheufler KM, Diesing D (2015) [Use of bone graft replacement in spinal fusions] Orthopade 44: 146-153.

Schlundt C, El Khassawna T, Serra A, Dienelt A, Wendler S, Schell H, van Rooijen N, Radbruch A, Lucius R, Hartmann S, Duda GN, Schmidt-Bleek K (2018) Macrophages in bone fracture healing: their essential role in endochondral ossification. Bone 106 : 78-89.

Shao M-H, Zhang F, Yin J, Xu H-C, Lyu F-Z (2017) Titanium cages versus autogenous iliac crest bone grafts in anterior cervical discectomy and fusion treatment of patients with cervical degenerative diseases: a systematic review and meta-analysis. Curr Med Res Opin 33: 803-811.

Stefanowski J, Lang A, Rauch A, Aulich L, Köhler M, Fiedler AF, Buttgereit F, Schmidt-Bleek K, Duda GN, Gaber T, Niesner RA, Hauser AE (2019) Spatial distribution of macrophages during callus formation and maturation reveals close crosstalk between macrophages and newly forming vessels. Front Immunol 10: 2588. DOI: 10.3389/fimmu.2019.02588.

Thalji G, Cooper LF (2014) Molecular assessment of osseointegration in vitro: a review of current literature. Int J Oral Maxillofac Implants 29: e171-e199.

Tylek T, Blum C, Hrynevich A, Schlegelmilch K, Schilling T, Dalton PD, Groll J (2020) Precisely defined fiber scaffolds with $40 \mu \mathrm{m}$ porosity induce elongation driven M2-like polarization of human macrophages. Biofabrication 12: 025007. DOI: 10.1088/1758-5090/ ab5f4e.

Urist MR (1965) Bone: formation by autoinduction. Science 150: 893-899.

Urist MR, Strates BS (1971) Bone morphogenetic protein. J Dent Res 50: 1392-1406.

van Dijk LA, Barbieri D, Barrère-de Groot F, Yuan H, Oliver R, Christou C, Walsh WR, de Bruijn JD (2019) Efficacy of a synthetic calcium phosphate with submicron surface topography as autograft extender in lapine posterolateral spinal fusion. J Biomed Mater Res B Appl Biomater 107: 2080-2090.

van Dijk LA, Barrère-De Groot F, Rosenberg AJWP, Pelletier M, Christou C, De Bruijn JD, Walsh WR (2020) MagnetOs, vitoss, and novabone in a multi-endpoint study of posterolateral fusion: a true fusion or not? Clin Spine Surg 33: E276-E287.

van Dijk LA, Duan R, Luo X, Barbieri D, Pelletier M, Christou C, Rosenberg AJWP, Yuan H, Barrèrre-de Groot F, Walsh WR, de Bruijn JD (2018) Biphasic calcium phosphate with submicron surface topography in an ovine model of instrumented posterolateral spinal fusion. JOR Spine 1: e1039. DOI: 10.1002/jsp2.1039.

Wang J, Qian S, Liu X, Xu L, Miao X, Xu Z, Cao L, Wang H, Jiang X (2017) M2 macrophages contribute to osteogenesis and angiogenesis on nanotubular TiO2 surfaces. J Mater Chem B 5: 3364-3376.

Wang T, Luu TU, Chen A, Khine M, Liu WF (2016) Topographical modulation of macrophage phenotype by shrink-film multi-scale wrinkles. Biomater Sci 4: 948-952.

Wang X, Wang Y, Bosshardt DD, Miron RJ, Zhang Y (2018) The role of macrophage polarization on fibroblast behavior-an in vitro investigation on titanium surfaces. Clin Oral Investig 22: 847-857.

Wang Z, Cui Y, Wang J, Yang X, Wu Y, Wang K, Gao X, Li D, Li Y, Zheng XL, Zhu Y, Kong D, Zhao $Q$ (2014) The effect of thick fibers and large pores of electrospun poly( $\varepsilon$-caprolactone) vascular grafts on macrophage polarization and arterial regeneration. Biomaterials 35: 5700-5710.

Wosik J, Chen W, Qin K, Ghobrial RM, Kubiak JZ, Kloc M (2018) Magnetic field changes macrophage phenotype. Biophys J 114: 2001-2013.

Wynn TA, Vannella KM (2016) Macrophages in tissue repair, regeneration, and fibrosis. Immunity 44: 450-462.

Xiao H, Guo Y, Li B, Li X, Wang Y, Han S, Cheng D, Shuai X (2020) M2-like tumor-associated macrophage-targeted codelivery of STAT6 inhibitor and IKK $\beta$ siRNA induces M2-to-M1 repolarization for cancer immunotherapy with low immune side effects. ACS Cent Sci 6: 1208-1222.

$\mathrm{Xu}$ WC, Dong $\mathrm{X}$, Ding JL, Liu JC, Xu JJ, Tang YH, Yi YP, Lu C, Yang W, Yang JS, Gong Y, Zhou JL (2019) Nanotubular TiO 2 regulates macrophage M2 polarization and increases macrophage secretion of vegf to accelerate endothelialization via the ERK1/2 and PI3K/AKT pathways. Int J Nanomedicine 14: 441-455.

Yamasaki H, Sakai H (1992) Osteogenic response to porous hydroxyapatite ceramics under the skin of dogs. Biomaterials 13: 308-312.

Yang C, Zhao C, Wang X, Shi M, Zhu Y, Jing L, Wu C, Chang J (2019) Stimulation of osteogenesis and angiogenesis by micro/nano hierarchical hydroxyapatite: via macrophage immunomodulation. Nanoscale 11: 17699-17708.

Yang Y, Lin Y, Zhang Z, Xu R, Yu X, Deng F (2021) Micro/nano-net guides M2-pattern macrophage cytoskeleton distribution via Src-ROCK signalling for enhanced angiogenesis. Biomater Sci 9: 3334-3347.

Yu WP, Ding JL, Liu XL, Zhu GD, Lin F, Xu JJ, Wang Z, Zhou JL (2021) Titanium dioxide nanotubes promote $\mathrm{M} 2$ polarization by inhibiting macrophage glycolysis and ultimately accelerate endothelialization. Immun Inflamm Dis. DOI: 10.1002/iid3.429.

Yuan H, Fernandes H, Habibovic P, De Boer J, Barradas AMC, De Ruiter A, Walsh WR, Van Blitterswijk CA, De Bruijn JD (2010) Osteoinductive ceramics as a synthetic alternative to autologous bone grafting. Proc Natl Acad Sci U S A 107: 13614-13619.

Yuan H, Kurashina K, De Bruijn JD, Li Y, De Groot K, Zhang X (1999) A preliminary study on osteoinduction of two kinds of calcium phosphate ceramics. Biomaterials 20: 1799-1806.

Zarif JC, Hernandez JR, Verdone JE, Campbell SP, Drake CG, Pienta KJ (2016) A phased strategy to differentiate human CD14+ monocytes into 
classically and alternatively activated macrophages and dendritic cells. Biotechniques 61: 33-41.

Zhang J, Shi H, Zhang N, Hu L, Jing W, Pan J (2020) Interleukin-4-loaded hydrogel scaffold regulates macrophages polarization to promote bone mesenchymal stem cells osteogenic differentiation via TGF- $\beta 1 /$ Smad pathway for repair of bone defect. Cell Prolif 53: e12907. DOI: 10.1111/cpr.12907.

Zhang R, Liang Y, Wei S (2018) M2 macrophages are closely associated with accelerated clavicle fracture healing in patients with traumatic brain injury: a retrospective cohort study. J Orthop Surg Res 13: 213. DOI: 10.1186/s13018-018-0926-7.

Zhao DW, Zuo KQ, Wang K, Sun ZY, Lu YP, Cheng L, Xiao GY, Liu C (2021) Interleukin-4 assisted calcium-strontium-zinc-phosphate coating induces controllable macrophage polarization and promotes osseointegration on titanium implant. Mater Sci Eng C Mater Biol Appl 118: 111512. DOI: 10.1016/j. msec.2020.111512.

Zheng ZW, Chen YH, Wu DY, Wang JB, Lv MM, Wang XS, Sun J, Zhang ZY (2018) Development of an accurate and proactive immunomodulatory strategy to improve bone substitute material-mediated osteogenesis and angiogenesis. Theranostics 8: 54825500.

Zhu Y, Liang H, Liu X, Wu J, Yang C, Wong TM, Kwan KYH, Cheung KMC, Wu S, Yeung KWK (2021) Regulation of macrophage polarization through surface topography design to facilitate implant-tobone osteointegration. Sci Adv. 7: eabf6654. DOI: 10.1126/sciadv.abf6654.

\section{Web References}

1. Kruyt M MagnetOs ${ }^{\mathrm{TM}}$ granules vs. autograft in instrumented posterolateral spinal fusion (MaxA). Identifier: NCT03625544. www.clinicaltrials.gov [1006-2021]

2. Kuros Biosciences (2019) Post marketing clinical follow up study for magnetos putty in patients with degenerative disc disease (PROGRESS). Identifier: NCT04128852. www.clinicaltrials.gov [10-06-2021]

\section{Discussion with Reviewers}

Reviewer 1: Please discuss the effect of nanoparticles/ submicron- versus micron-sized calcium phosphate/ hydroxyapatite and the different shapes of these particles on bone repair.
Authors: As covered in the present review, recent research has been consistent in demonstrating a relationship between topography, cell shape and macrophage phenotype (McWhorter et al., 2013; Wang et al., 2016). Various materials with specific structural or topographical features have been shown to modulate the shape of adherent macrophages as well as their phenotype. Although the involved signalling pathways have not yet been fully identified, it is probable that material structural features can induce macrophage polarisation by modulating cell shape, which through mechanotransduction pathways may lead to altered downstream signalling.

Reviewer 2: Would the authors consider relevant the presence of osteoclast in the process of bone regeneration? Why?

Authors: The presence of osteoclasts is considered very relevant in the process of bone regeneration with calcium phosphate biomaterials. Previous research has suggested that osteoclastogenesis precedes material-directed bone formation by osteoinductive calcium phosphates (Davison et al., 2014a; Miron et al., 2016, additional reference). The in vivo data obtained in the canine model described in the present review also suggested a role of osteoclasts prior to osteoinductive bone formation. In addition, research that evaluated the response of macrophages to calcium phosphates with osteoinductive capacity has demonstrated clear effects of surface structure on osteoclast activity (Davison et al., 2014b; 2014c). Since osteoclasts are derived from the monocyte/ macrophage lineage, it is probable that when macrophages polarise in response to specific material topographies, this will similarly affect fusion behaviour of these macrophages to form osteoclasts. However, very little research has been done on the relationship between macrophage phenotype and differentiation into osteoclasts.

\section{Additional Reference}

Miron RJ, Zohdi H, Fujioka-Kobayashi M, Bosshardt DD (2016)Giant cells around bone biomaterials: Osteoclasts or multi-nucleated giant cells? Acta Biomater 46: 15-28.

Editor's note: The Scientific Editor responsible for this paper was Chris Evans. 